\title{
Los arcaduces islámicos de Senda de Gra- nada. Tipología y encuadre cronológico
}

\author{
The islamic arcaduces of Senda de Granada. Typological and chronolo- \\ gical adscription
}

Luis A. García Blánquez*

\begin{abstract}
RESUMEN
Este trabajo se centra en los arcaduces documentados en un conjunto de aceñas localizadas en Senda de Granada, un paraje emplazado en el heredamiento norte del sistema hidráulico andalusí murciano.

El estudio del material cerámico y el análisis de los contextos estratigráficos y estructurales han permitido confirmar la filiación islámica, al menos del heredamiento de Aljufía (norte), y su datación en el siglo X, descartando su posible origen romano. Esta fecha se ha podido establecer gracias a los arcaduces documentados en las aceñas 1,2 y 3 , que denominamos arcaduces de fijación próximodistal, que se encuadran tipológicamente en el grupo identificado por S. Gutiérrez Lloret (1986, 1996), en el Bajo Segura, cuyos antecedentes se remontan a la segunda mitad del siglo VIII.
\end{abstract}

La presencia en Senda de Granada de otro tipo de arcaduz, provisto de sendas escotaduras y base apuntada (engarce próximo-medial), mejor representado en el resto de al-Andalus, nos llevó a estudiar la distribución espacial de los respectivos tipos y el supuesto proceso evolutivo de carácter morfo-técnico. El análisis ha revelado que ambos tipos de arcaduz convivieron un largo período de tiempo, entre los siglos X y XI, aunque no en el mismo espacio geográfico, sino que ocuparon zonas excluyentes hasta que hacia el siglo XII los arcaduces de amarre próximo-distal fueron definitivamente remplazados, en Tudmīr, por los de fijación próximo-medial de base apuntada.

En relación con la creación del espacio irrigado andalusí en Murcia, los hallazgos de Senda de Granada permiten determinar un terminus ante quem para la creación de su huerta en el siglo X, período en el cual sus aceñas ya se encontraban funcionando.

Palabras clave: arcaduz (qâdûs), cerámica, aceña (sâniya), irrigación, islámico.

\begin{abstract}
This essay focuses its study in the arcaduces (qâdûs: islamic ceramic waterwheel buckets) documented in a set of aceñas (Sâniya: water-lifting wheels draught by animals) located in Senda de Granada, an area based in the northern zone of the AndalusianMurcian hydraulic system.
\end{abstract}

The study of the ceramic material and the analysis of the stratigraphic and structural contexts have confirmed the islamic affiliation of, at least, the zone of Aljufía (north), and its dating in the X century, ruling out its possible Roman origin. This date has been established thanks to the documented arcaduces in the aceñas 1, 2 and 3, which are denominated arcaduces of near-distal fixation and are typologically located in the group identified by S. Gutiérrez Lloret (1986, 1996), originally, in the Lower Segura river, which traces its history back to the second half of VIII century.

The presence of other kind of arcaduz in Senda de Granada, provided of notches and a pointed base (near-medial fixation), better represented in the rest of al-Andalus, led us to study the spatial distribution of the respective types and the alleged evolutionary process of morpho-technical character. The analysis has revealed that both types of arcaduz lived together for a long period of time, between the X and XI centuries, although they didn't coexisted at the same geographic space. They occupied exclusive areas until the XII century, when the near-distal fixation arcaduces were definitely replaced, in Tudmīr, by the near-medial fixation arcaduces with pointed base.

In relation with the creation of the al-Andalus irrigated space in Murcia, the findings in Senda de Granada make possible to determine a terminus ante quem for the creation of their vegetable garden in the X century, period in which their aceñas were already operating.

Key words: bucket (qâdûs), islamic ceramics, waterlifting wheels by draught animals (sâniya), irrigation.

\footnotetext{
* Arqueólogo codirector de ArqueoTec.

Quiero expresar mi más sincero agradecimiento a los evaluadores por sus sugerencias y observaciones a nuestro borrador, que nos han animado ampliar el ámbito espacial de nuestra investigación enriqueciendo su contenido, y al Consejo de Redacción de la revista. Así mismo debo expresar mi reconocimiento a Da Sonia Gutiérrez Lloret por la atenta lectura del borrador, sus acertadas reflexiones y consejos en un tema que conoce profundamente, y a Don Jorge A. Eiroa Rodríguez que nos animó a dar conocer "El sistema hidráulico andalusí de Senda de Granada”, en el seminario “Novedades Arqueológicas en al-Andalus” Museo Santa Clara de Murcia.
} 


\section{EL YACIMIENTO}

El hallazgo fortuito de una sepultura tardorromana en el curso de las obras de urbanización en el Plan Parcial U.A. I ZA-Ed3 Espinardo (Murcia) (Fig. 1), puso al descubierto la existencia de un yacimiento del que no se tenía noticia previa y, por tanto, no se encontraba bajo control administrativo ${ }^{1}$.

\subsection{El espacio físico}

Sus vestigios se extienden por una antigua zona de huerta ${ }^{2}$, con un suave declive sur-sureste, organizada en dos terrazas articuladas por el curso antiguo de la acequia Alfatego. La septentrional, delimitada al norte a su vez por la acequia Churra la Vieja, se sitúa en torno a los 50/51 m de altitud sobre el nivel del mar $^{3}$, mientras que en la meridional el terreno desciende desde los $49 \mathrm{~m}$ hasta los $45 \mathrm{~m}^{4}$.

Desde el punto de vista geomorfológico el emplazamiento arqueológico se ubica en el borde noroccidental de la llanura de inundación holocena del Río Segura, sobre una superficie inclinada hacia el sureste, que corresponde a los abanicos aluviales ligados a los sistemas de drenaje transversal de la red hídrica principal (río Segura) ${ }^{5}$, formados por la rambla de Espinardo (también Mondexar)

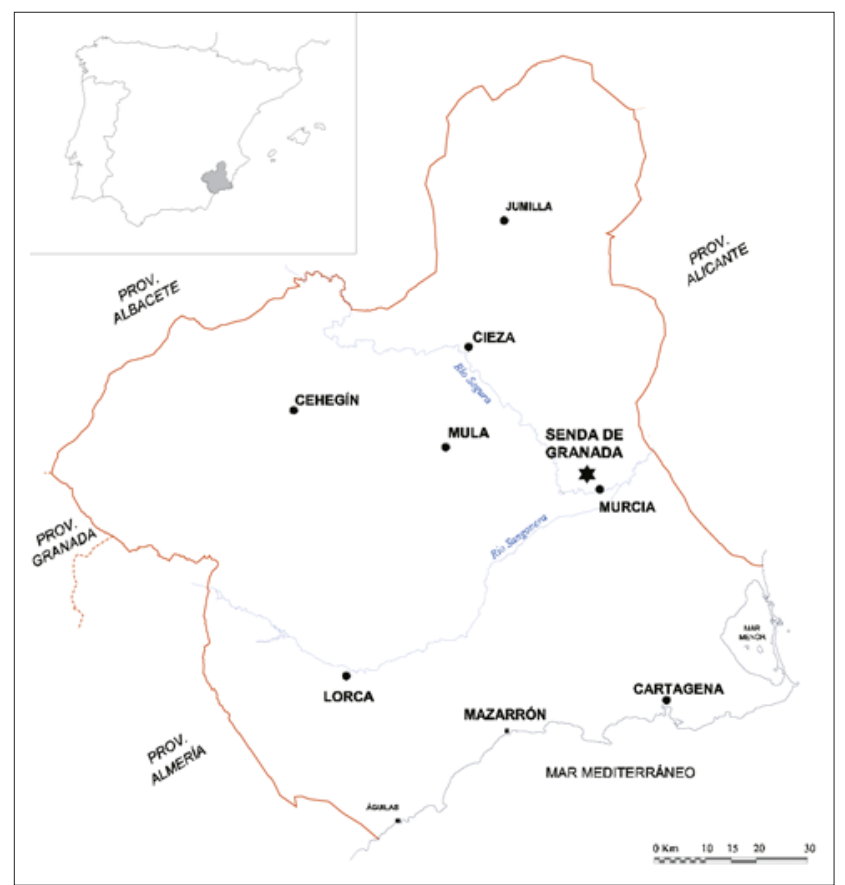

Figura 1. Localización regional de Senda de Granada en Espinardo (Murcia).

que transcurre al este, entre las calles de esta población, y la ya parcialmente desaparecida de Los Lisones ${ }^{6}$ que confluía con el anterior en esta zona por el oeste.

El estudio sedimentológico ha constatado que el abanico aluvial de Espinardo se mantenía activo cuando la zona fue ocupada en época romana (PÉREZ VALERA, e.p.). Anteriormente la acción erosiva remontante había modelado el frente del abanico aluvial creando un relieve de pequeñas lomas de escasa altura,

1 El Plan Parcial U.A. I ZA-Ed3 Espinardo (Murcia), con una superficie de actuación global de 163.531 m2, está integrado por un sector residencial (109.401 m2), otro de equipamientos (12.130 m2) y una zona verde (S.G. de Espacios Libres, 42.000 m2). La prospección sistemática de cobertura total y la posterior ejecución de un amplio programa de sondeos arqueológicos para evaluar su extensión, naturaleza y estado de conservación, llevó a la Dirección General de Cultura de la Región de Murcia a resolver diversas fórmulas de documentación arqueológica del espacio edificable, previo a su autorización definitiva. Tras numerosas vicisitudes los trabajos de excavación dieron comienzo en enero de 2007 y finalizaron en julio de 2008, sucediéndose entre ambas fechas varias interrupciones de diversa duración. La promoción urbanística de Viviendas de Protección Oficial ha sido realizada por Joven Futura, Sociedad Cooperativa de Viviendas, entidad que ha financiado, en exclusiva, todos los trabajos arqueológicos de investigación.

2 La intervención arqueológica se ciñen sólo al ámbito del plan urbanístico y no se descarta, pues, que sus vestigios se extiendan más allá de los límites de nuestra intervención. La extensión de terreno con indicios arqueológicos parece mayor, pues algunos restos arquitectónicos y dos de sus cementerios ocupan lugares periféricos con visos de continuidad fuera del área estudiada.

3 En adelante, aunque no se indique, todas las medidas de altitud van referidas al nivel del mar.

4 La zona arqueológica queda definida al sur y el oeste por la Autovía Murcia-Alicante (A-30); por la calle Dr. de la Peña y el curso soterrado de la acequia Churra la Vieja, al norte y el camino Antena Radio Murcia, por levante

5 Pérez Valera, F. (e.p.): "Estudio geológico y sedimentológico de los materiales sedimentarios relacionados con el yacimiento arqueológico <<Senda de Granada>>, Espinardo (Murcia)".

6 Véase Mapa de la Jurisdición de la Villa de Espinardo (1723). 
surcadas por vaguadas intermedias poco profundas que, conforme avanzan hacia el sur, ganaban en amplitud dando paso a una planicie levemente inclinada hacia el sureste ${ }^{7}$. El paisaje de la zona mostraba altozanos, probablemente amesetados, que fueron aprovechados para ubicar algunas construcciones de mayor envergadura, mientras que las zonas bajas intermedias albergaron áreas de trabajo, en tanto que en las llanas se instaló un hábitat de carácter muy modesto (Fig. 2). Entre el abandono en época visigoda (en los inicios del s. VII) y el momento inicial de la ocupación medieval islámica, no se constata ningún proceso de aterramiento natural en la zona centro-meridional ${ }^{8}$, si bien posteriormente como consecuencia de la instauración del sistema de irrigación se produjeron importantes aportes de limos acarreados por las propias acequias de riego que obligaron, incluso, a construir nuevos trazados para sustituir aquellos que quedaban entarquinados ${ }^{9}$.

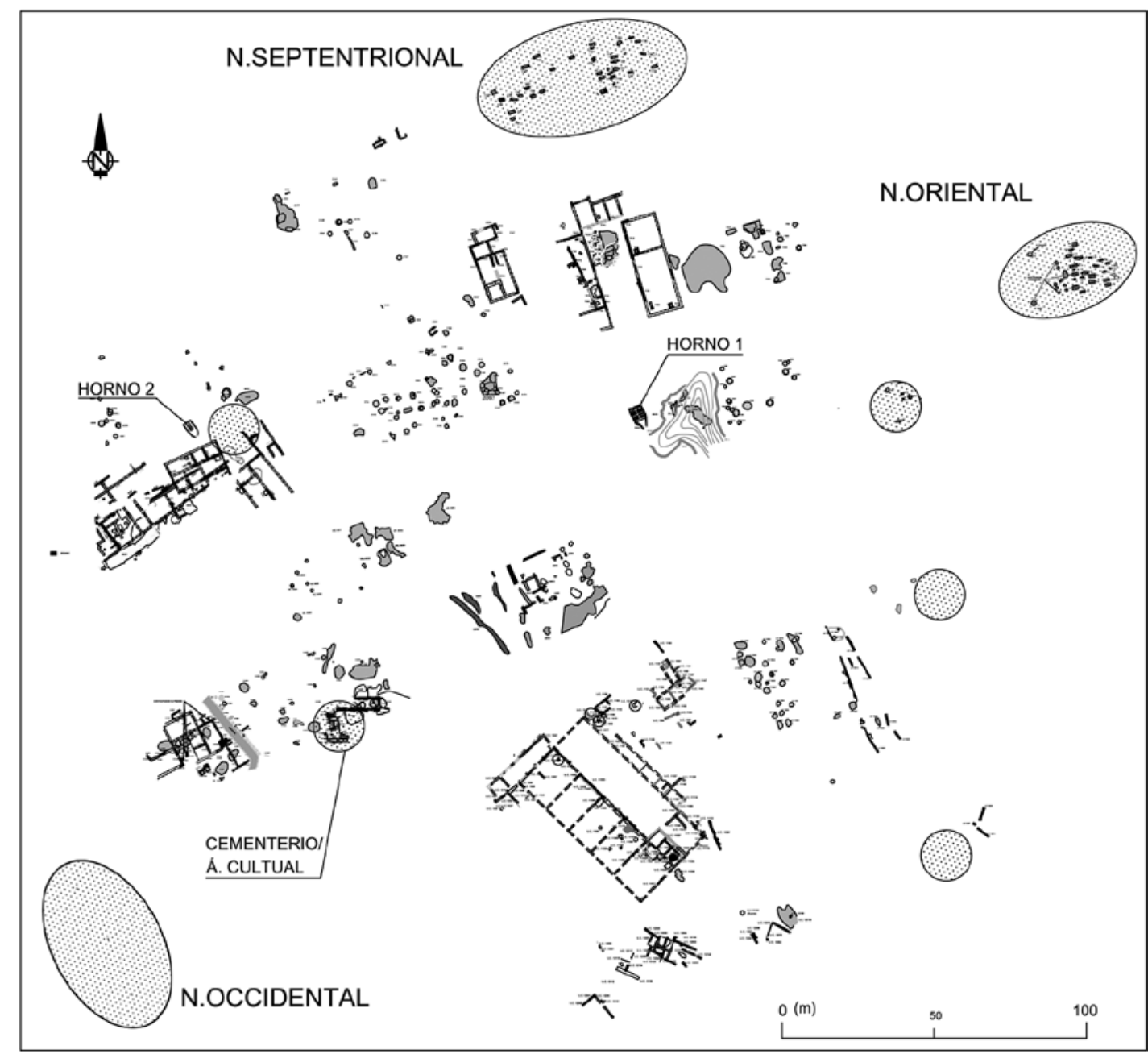

Figura 2. Planta general de Senda de Granada en Espinardo (Murcia) con indicación de las necrópolis, enterramientos aislados y sectores alfareros.

7 Para restituir y plasmar el relieve antiguo en un plano topográfico se han registrado las cotas de las estructuras arquitectónicas y de los niveles de frecuentación conservados y, en aquellas zonas donde no se conservaban o no existían éstos, se ha registrado la cota más alta de las estructuras excavadas en el suelo.

8 En algunos sectores de excavación se ha documentado la superposición directa de niveles islámicos, prácticamente en contacto, sobre los vertederos tardoantiguos sin apenas sedimentación. Esto se constata a mediodía de la aceña 3 (sector B), vertederos orientales en F1 y en los niveles de abandono de la posible almazara de E1.

9 De tarquín. Término empleado repetidamente en las fuentes bajomedievales para indicar el súbito aterramiento de los cauces de las acequias y las parcelas de cultivo por lodos y limos aportados por las riadas (aguaduchos). 


\subsection{Fases de ocupación}

El sector excavado de Senda de Granada corresponde a la pars fructuaria de una probable villa rural romana que podemos datar entre el siglo IV y finales del siglo VI o principios del VII (GARCÍA BLÁNQUEZ, 2010) (Fig. 2). El momento de su fundación queda impreciso, aunque la presencia de material cerámico residual (ss. I-III) localizado en algunos depósitos-vertedero bien fechados ${ }^{10}$, sugiere que el enclave fue fundado hacia el siglo I de nuestra era ${ }^{11}$.

A principios del siglo VII, coincidiendo probablemente con la conquista y destrucción de la bizantina Carthago Spartaria a manos de los godos (Suintila/Sisebuto), este antiguo establecimiento tardorromano quedó definitivamente abandonado. Este hecho se refleja en el registro material de la fase de abandono (finales del siglo VI) donde se constata la ausencia de vajilla de mesa y ánforas de importación propias del siglo VII, así como en los contextos cerámicos de etapas inmediatamente posteriores (s. VIII), como el documentado en el cercano yacimiento del Tolmo de Minateda integrado por botellas, ollas de borde vuelto con asitas, jarros, etcétera (ALBA Y GUTIÉRREZ, 2008, f. 2; AMORÓS et alii, 2012, 246-7, f. 2).

Tras el abandono a comienzos del siglo VII, el despoblado quedó expuesto hasta bien avanzado el siglo IX o, incluso, primeras décadas del X. Es en este momento cuando detectamos un conjunto de estructuras hidráulicas que transforman la zona en un espacio agrícola irrigado. Hacia la segunda mitad del siglo XII y principios del XIII, la zona o mejor su entorno inmediato, vuelve a ser poblada de nuevo, aunque de este espacio residencial sólo tenemos constancia de forma indirecta gracias a un pequeño grupo de silos localizados al este, que contenían algunos elementos constructivos entre otros materiales domésticos de desecho.

El emplazamiento de la zona de residencia de la comunidad campesina islámica más próximo, cuya existencia deducimos sólo por la presencia de vajilla doméstica, debe localizarse en un punto cercano, quizás fuera del espacio irrigado, probablemente aguas arriba de la línea de rigidez (BARCELó PERELLÓ, 1989). Así pues, todas las estructuras hidráulicas que se han documentado se construyeron bien desmantelando antiguas instalaciones productivas tardorromanas, bien sobre los niveles de abandono de la ocupación tardoantigua. El área donde se construyen las aceñas 1 y 2 , era un espacio sin estructuras que había dejado de frecuentarse hacia la primera mitad del siglo VI. La aceña 3 se instaló sobre una terraza que daba paso a una planicie repleta de silos, vertederos y áreas de combustión en uso desde finales del siglo IV hasta el siglo VI. Y la toma de la aceña 4 y el tablacho, estaban articulados por una acequia que seccionaba la parte oriental de una probable instalación aceitera.

La conquista cristiana (1243) y el reparto de tierras posterior, otorgaba a los mursíes/mursyes árabes esta zona de la huerta murciana (heredamiento norte), permaneciendo en sus manos propiedades y derechos de explotación. Sin embargo, tras la revuelta mudéjar de 1264, la consiguiente pérdida de sus privilegios ocasionó el progresivo éxodo de la población

\footnotetext{
10 En la parte oriental del sector E1 se han localizado alguno de estos depósitos altoimperiales, como el silo-vertedero 8019 -con 2 fragmentos de TS Sudgálica Drag. 18A (15-60) y Drag. 37A (60-100)- o el vertedero 8053 que cuenta con varios niveles de deposición, desde el nivel inferior inicial (8143) con un interesante lote de cerámica altoimperial -TSA A, tipos H. 14B (160-200), H. 14 (150-200) y H. 14A (150) TSA C, H. 50B (350-400), H. 50A (300-360), H. 46 (275-325) y cocina africana tipos Ostia I, 261, Ostia I, 332 y H. 27 (160-220)- junto a 2 fragmentos de alfiler tallado en hueso (acus crinalis) y restos de conchas marinas, hasta su abandono final entre la segunda mitad del siglo IV o inicios del V (TSA D H. 59B (320-420) TSA C H. 50B (350-400).

11 En el curso de la excavación no se han encontrado evidencias materiales o estructurales de la zona señorial del establecimiento (pars urbana). A pesar de ello, no dudamos de su existencia y no descartamos que en el futuro se localicen los restos fundacionales de este enclave en el entorno de nuestra zona de estudio. Aunque desconocemos su posible ubicación, por razones de salubridad (Columella 12 libros. Libro I, V.), la pars urbana, habría de situarse a favor de los vientos dominantes, es decir, al este o al sur de su pars fructuaria. No obstante, no descartamos ninguna zona en tanto no se compruebe arqueológicamente.
} 
musulmana. Hacia finales del siglo XIII o inicios del XIV la zona vuelve a quedar despoblada, sin que tengamos constancia material de la llegada de repobladores cristianos.

Finalmente, hacia mediados del siglo $\mathrm{XVI}$, se hace palpable de nuevo la presencia humana en la cercana población de Torre de Espinardo ${ }^{12}$, situada al noreste de Senda de Granada. Y a mediados del siglo XVIII, el Catastro del Marqués de la Ensenada, nos informa de la continuidad del uso agrario instaurado por los árabes y su evolución posterior: "las tierras de esta villa son de Regadío y Secano, que en el Regadio las ay de Labrado Moreral, olivar, viñas y Frutales y en el Secano las ay de Labrado olivar montevajo y Inutil"... ${ }^{13}$

\section{EL SISTEMA HIDRÁULICO EN SENDA DE GRANADA. ACEQUIAS Y ACEÑAS}

En esta zona el sistema de riego actual está constituido por las acequias Churra la Vieja y Alfatego, situadas, respectivamente, al norte y en el centro de la zona de estudio que nos ocupa ${ }^{14}$. Ambos cauces pertenecen al heredamiento norte del milenario sistema de riego de la huerta de Murcia (Fig. 3). Éste tiene su origen en el denominado azud de la

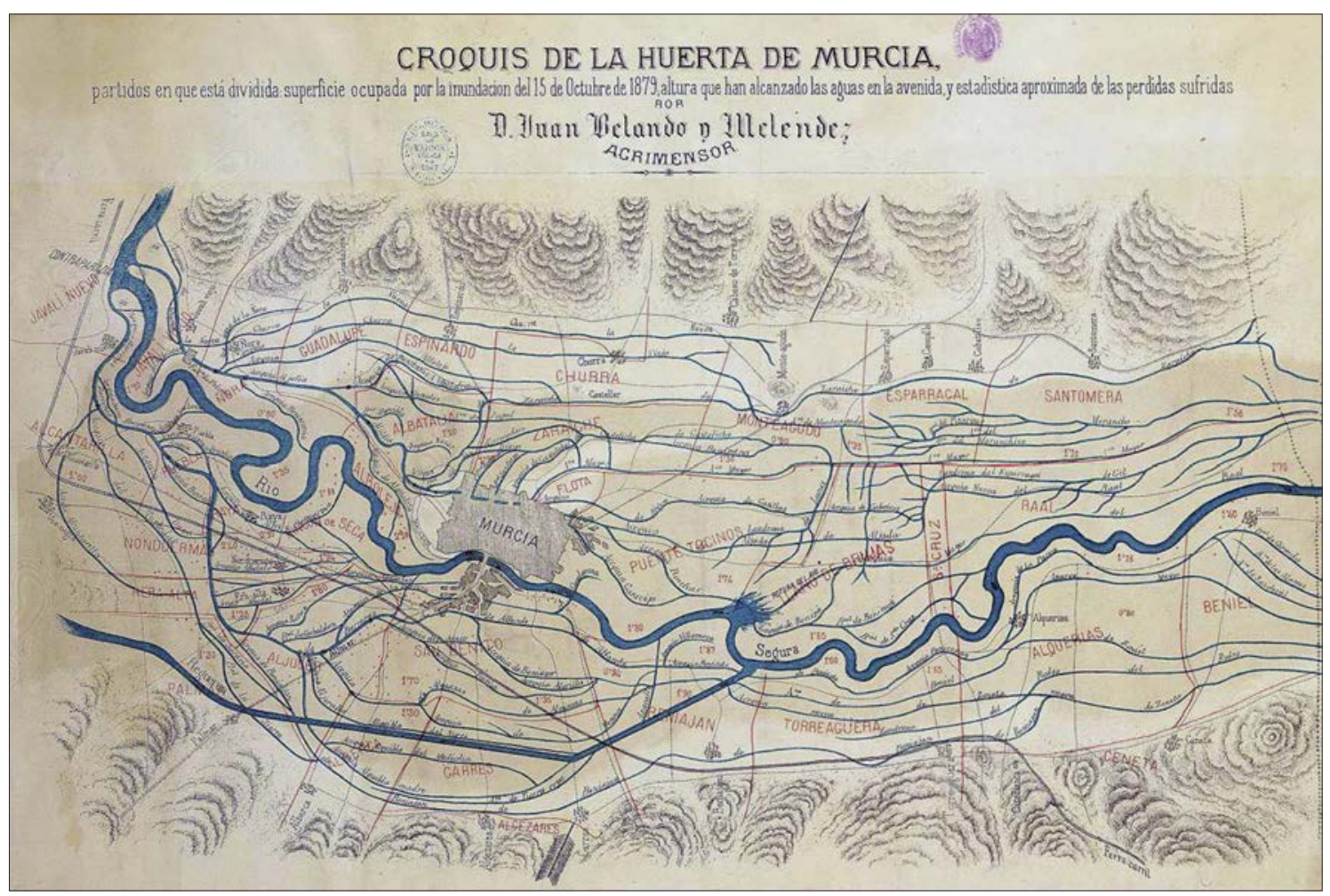

Figura 3. Esquema del sistema hidráulico de la huerta de Murcia representado a finales del siglo XIX con motivo de la riada de Santa Teresa (J. Belando y Meléndez, 1879).

12 En el Repertorio de todos los caminos de España editado por Juan de Villuga en 1546, figura "Torre de Espinardo" en la ruta de Murcia a Toledo. Hacia 1542 el padrón de la parroquia de San Andrés de Murcia, de la que dependía Espinardo, ya contaba con 11 vecinos (http://geneaguerrero.es.tl)

13 Respuestas Generales del Catastro del Marqués de la Ensenada, Localidad: Espinardo, Provincia: Murcia. (AGS_CE_RG_L463_480/487) Archivo General de Simancas (http://pares.mcu.es/Catastro)

14 Véase Mapa de la Jurisdicción de la Villa de Espinardo, 1728 y Croquis de los Cauces de Riego de la Huerta de Murcia (Belando, 1878 , 80), CROQUIS DE LA ZONA INUNDADA en la Huerta de Murcia y Provincia de Alicante, en 15 de Octubre de 1879 (1881) y CROQUIS DE LA HUERTA DE MURCIA,1879 (Belando, 1879) 
Contraparada ${ }^{15}$, situado en el río Segura a 8 km, junto a la población de Javalí Nuevo. En el azud Mayor y en la Contraparada tienen respectivamente su toma las acequias madre, arterias principales que abastecen cada uno de los sectores en los que queda dividido el regadío murciano: los heredamientos de Mediodía (Alquibla) y del Norte (Aljufía) ${ }^{16}$.

En la margen izquierda de la acequia madre de Aljufía toman agua, primero, la acequia Churra la Vieja y, unos metros más abajo, la acequia Alfatego, a la que se atribuye mayor antigüedad (POCKLINGTON 1990, p.165). Ambas acequias circulan en paralelo y a corta distancia entre sí a su paso por la zona de estudio. Churra la Vieja transita por el norte cerca de la parte meridional de la población de Espinardo, con dirección NE y a una cota de 51/50 m de altitud, y Alfatego, desplazada algo hacia el sur, a un nivel inferior (49/48 $\mathrm{m})^{17}$. Además, el antiguo sistema hidráulico andalusí contaba aquí con un tercer canal de riego, ahora amortizado, que denominamos provisionalmente acequia del Tablacho (correspondiente a un trazado antiguo de la acequia Alfatego) (Fig. 4).

Junto a estas acequias se halló un conjunto de estructuras hidráulicas singulares: cuatro

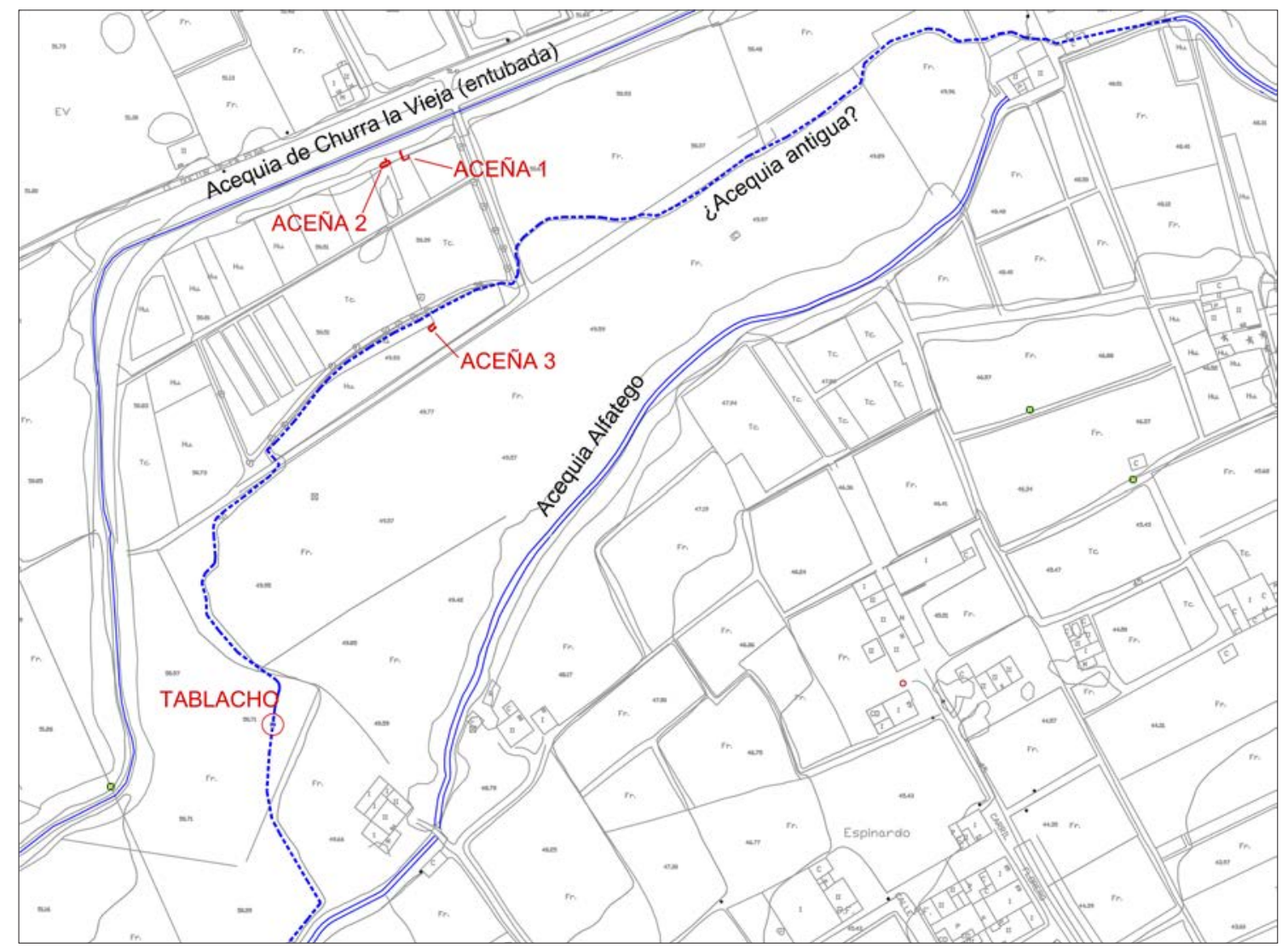

Figura 4. Localización de las estructuras hidráulicas (aceñas y compuerta) entre las acequias Churra la Vieja (norte) y Alfatego (sur), en un sector del heredamiento norte de la huerta de Murcia.

15 La Contraparada es, junto con el azud Mayor y el Muro de Luzón, uno los principales elementos del complejo hidráulico y, seguramente, el más peculiar de todos ellos. Se trata de una estructura de vital importancia cuya función originaria era facilitar la entrada de agua en la acequia madre de Aljufía, a través de un canal excavado en la roca (S. XV), conocido como Riacho. La "contraparada" era en realidad una presa-aliviadero o presa-fusible, construida aguas arriba del azud Mayor, que ha terminado por dar su nombre a todo el conjunto hidráulico.

16 En 1877 el azud de la Contraparada regaba 102.088 tahúllas en la Huerta de Murcia y 6.479 tahúllas en la Huerta y término de Orihuela (en total 108.567 tahúllas), abarcando una extensión conjunta de 12.137 Ha (Díaz Cassou, 1879, p. 59)

17 Los trayectos de ambos cursos circulan muy cerca en este sector, oscilando su proximidad entre 70 y $140 \mathrm{~m}$. 
aceñas y una compuerta (tablacho) ${ }^{18}$. En el margen derecho de Churra la Vieja se localizan las aceñas 1 y 2 . La aceña número 3 , aparentemente aislada, $60 \mathrm{~m}$ al sur de éstas y la toma de la aceña 4 y la compuerta, situados a casi dos centenares de metros al suroeste de las primeras, se encuentran en el mismo lecho de la denominada acequia del Tablacho (tramo antiguo de Alfatego).

La aceña 1 está formada por un pozo de planta rectangular con los extremos redondeados de 2,36 m de largo por 0,78 m de ancho ${ }^{19}$, construido con fábrica de mampostería tomada con argamasa de cal y barro (lados menores), con piedra menuda y pequeñas lajas formando una fábrica en espiga (Fig. 5). El fondo está constituido por el propio substrato arcilloso sin ningún tipo de preparado. En el vértice NO del pozo se abre un canal subteráneo de $3 \mathrm{~m}$ de longitud, con una cañería de 1,64 $\mathrm{m}$ de longitud formada por 5 atanores de cerámica de $30 \mathrm{~cm}$ de longitud y $26 \mathrm{~cm}$ de diámetro con refuerzos anulares en las embocaduras de $2 \mathrm{~cm}$ de grosor, decorados a peine con bandas incisas onduladas y rectas
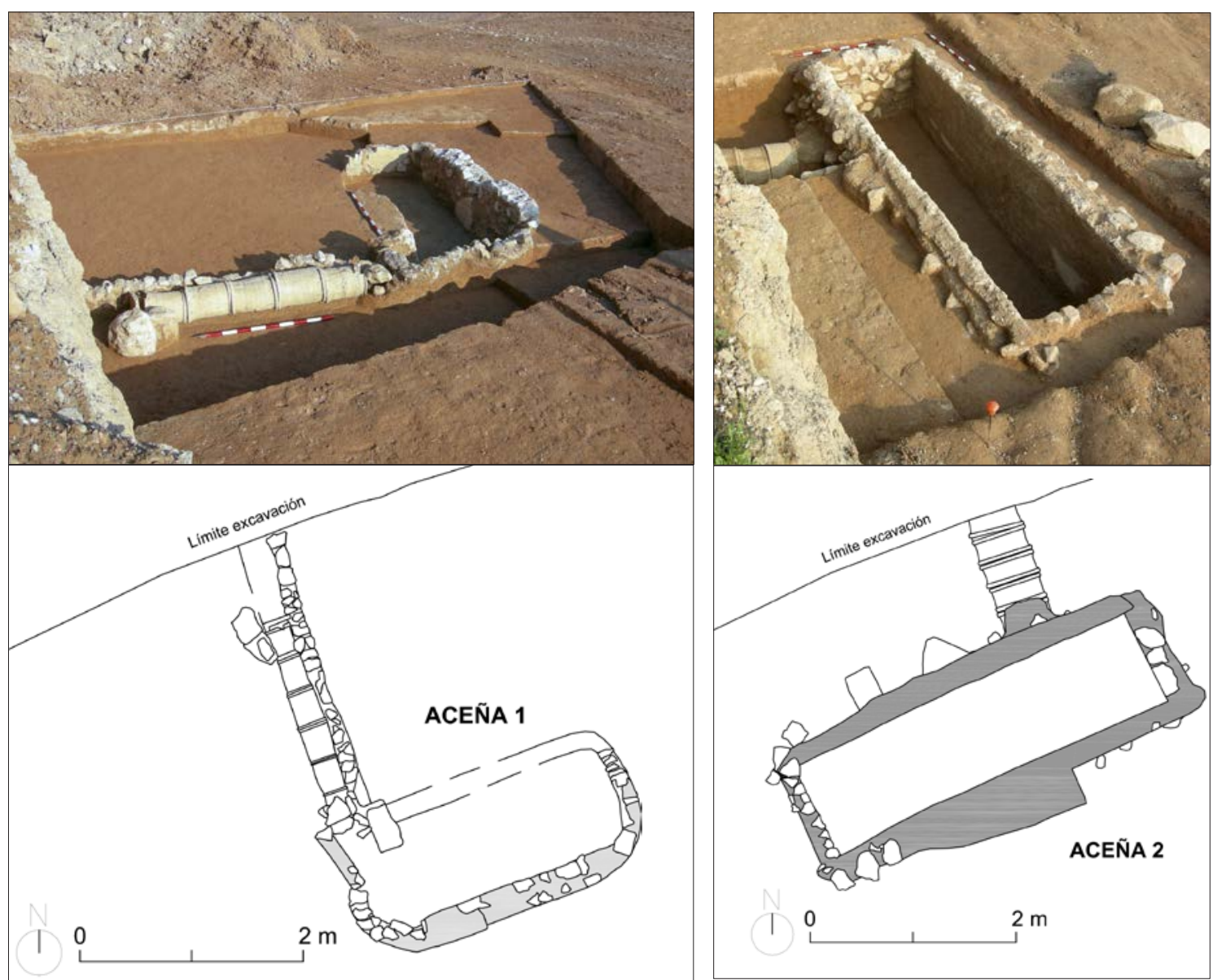

Figura 5. La aceña I (izquierda) conserva parcialmente el pozo de extremos redondeados y el conducto de atanores cerámicos decorados. El pozo rectangular de la aceña 2 (derecha) comunica con la acequia mediante un grueso conducto de atanores lisos.

18 La aceñas de Senda de Granada, que en adelante vamos a describir de modo sucinto, son objeto actualmente de un estudio específico. En esta ocasión, para evitar desviarnos del tema central del trabajo que nos ocupa, hemos omitido las referencias a otras estructuras hidráulicas, no sólo en el ámbito de la cercana Madinat Mursiya -Baños de San Nicolás (NAVARRO y ROBLES, 1993); Plaza de las Balsas 15 (ROBLES et alii, 1995)- sino del resto del al-Andalus, especialmente el pozo rectangular de la aceña del conjunto de los Albercones de la Alhamabra (MALPICA CUELLO, 1991), con el que nuestras aceña no 2 y 3 guarda cierta similitud tipológica.

19 Coordenadas absolutas UTM ED50 30N de la intersección del conducto subterráneo con el lado septentrional: x: 661751 , y: 4208142. 
alternas ${ }^{20}$. En su interior el pozo presentaba relleno con piedras y trozos de argamasa provenientes de la destrucción de sus propias paredes, entremezclados con fragmentos de arcaduces de noria de cuerpo cónico terminado en su base con un grosero y tosco botón irregular (uid. infra).

La aceña 2, como la anterior, está compuesta por un pozo y una conducción subterránea ${ }^{21}$. El pozo de planta rectangular tiene 3,48 $\mathrm{m}$ de longitud por 0,9 $\mathrm{m}$ de anchura (Fig. 5). Está construido con hormigón/mampostería encofrada, pero no conserva su altura original, restándonos sólo 1,05 m de su alzado ${ }^{22}$. El fondo está constituido por las mismas arcillas naturales en las que se encuentran excavados y cimentados los muros perimetrales. El conducto subterráneo parte de la cara septentrional del pozo de la aceña y se dirige hacia la acequia Churra la Vieja que discurre unos metros al norte. La parte visible de esta conducción está hecha con cinco atanores de cerámica ${ }^{23}$. Cada pieza cilíndrica tiene $0,48 \mathrm{~m}$ de diámetro, 0,23 m de altura y $3 \mathrm{~cm}$ de espesor. Sus extremos están reforzados con bordes engrosados de sección cuadrada. Sus paredes externas son lisas y carecen de ornamentación.

Por dentro el pozo se hallaba totalmente amortizado con abundantes restos cerámicos y grandes trozos de material constructivo. Los primeros están representados exclusivamente por fragmentos de arcaduces de gran tamaño similares a los de la aceña 1 de cuerpo troncocónico, de tendencia fusiforme, terminado en un grueso botón basal similar a la contera de un ánfora romana.

La aceña 3 conserva dos tipos de fábrica diferente, cuya técnica podemos equiparar, respectivamente, a las documentadas en el conjunto septentrional (aceñas 1 y 2) (Fig. 6).

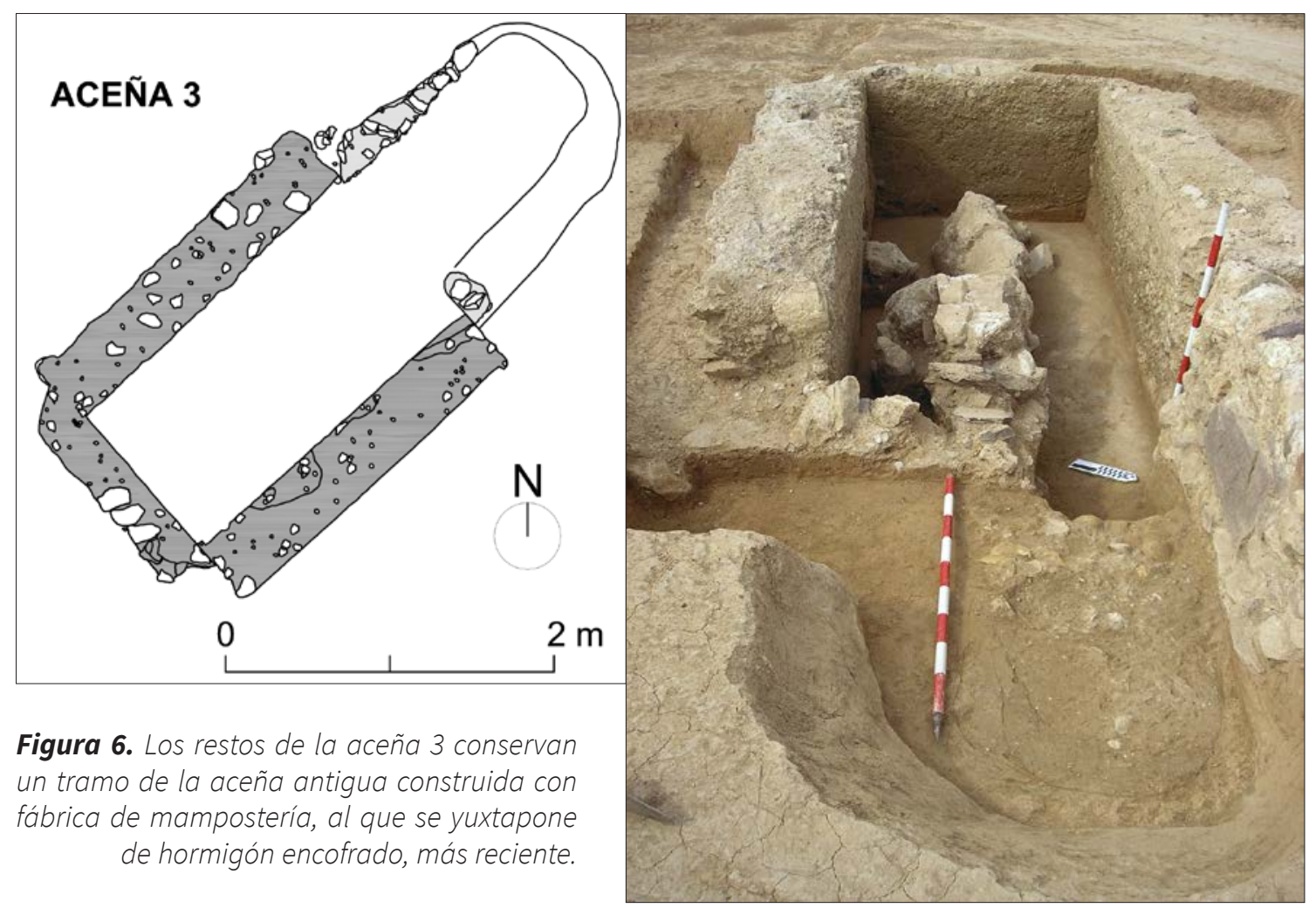

20 La decoración ondulada a peine es característica de las marmitas del siglo X. Este indicio junto con la técnica constructiva del pozo confirmarían la datación antigua de esta aceña, respecto de las demás.

21 Coordenadas absolutas UTM ED50 30N de la intersección del conducto subterráneo con el muro septentrional: x: 661745, y: 4208140. 22 La cota más alta de la estructura conservada de la aceña se sitúa a 49,20 m.

23 Son similares a los que conocemos como anillos de pozo de aguas limpias documentados en las casas islámicas de Murcia. 
La mitad sudoccidental del pozo se ha levantado con hormigón encofrado, mientras que el otro extremo se realizó con un tipo peculiar de mampostería en spicatum ${ }^{24}$ idéntica a la de la aceña 1.

En la mitad oriental del pozo se conserva la peculiar fábrica de mampostería caracterizada por el empleo de grandes placas de esquisto colocadas de cara y de hiladas irregulares dispuestas en espiga ${ }^{25}$. El extremo sudoccidental se conserva en mejor estado. Los tres paramentos están hechos con hormigón encofrado. Definen una planta rectangular de 2,12 $\mathrm{m}$ de longitud por 1,10 $\mathrm{m}$ de anchura (medidas internas). Tampoco se conserva completo el alzado del pozo, del que sólo se ha podido documentar un tramo de 0,76/0,80 $\mathrm{cm}^{26}$ de altura de su parte más profunda. Las arcillas naturales, como en los casos anteriores, forman el fondo sin ningún otro tipo de revestimiento ${ }^{27}$. En este caso no se documentó la cañería subterránea ni su entrada en el pozo.

Como en los casos anteriores la estructura también se hallaba rellena con trozos de fábrica de los propios muros, piedras y gran cantidad de arcaduces fragmentados. Los arcaduces documentados aquí son diferentes, variando ostensiblemente su forma que pasa a tener cuerpo cilíndrico con escotadura central, borde vuelto, hombro carenado y base puntiaguda con perfil en ojiva. De forma minoritaria también se hallaron arcaduces similares a los registrados en la aceña 1 y 2 , de cuerpo troncocónico, tendencia fusiforme y hombro redondeado, terminados en un grueso botón de tendencia esférica, cilíndrica o troncocónica.
A unos 150 metros al SO de la anterior se localiza la toma de la aceña 4, formada por un muro y un conducto subterráneo 28 (Fig. 7). Se trata de un paramento encofrado de 4,27 m de longitud, 1,07 $\mathrm{m}$ altura y $0,45 \mathrm{~m}$ de anchura (orientación SE-NO), de la que se conserva un tramo de dos cajones de largo por otros tantos de altura.

Al contrario que sucede en los casos anteriores (aceñas 1, 2 y 3), en esta ocasión se conserva la toma de agua situada dentro de la acequia y el conducto subterráneo, pero no el pozo de la aceña. La cañería está construida con atanores de cerámica similares a los de la aceña 1, en este caso, sin decorar ${ }^{29}$. El conducto soterrado conserva una longitud total de 3,73 m, de los cuales $0,45 \mathrm{~m}$ se hallan bajo el muro y $0,58 \mathrm{~m}$ dentro de la acequia. En la fábrica del muro quedaron integrados atanory medio y dentro del cauce otros tantos. En esta parte los tubos están recubiertos con argamasa, piedra y trozos de cerámica, mientras que la propia embocadura quedaba protegida lateralmente con sendos refuerzos de piedra y mortero, junto a la que se halló un fragmento de galbo de la parte inferior de un arcaduz de base apuntada y escotadura central.

Unas decenas de metros al SO, en el mismo cauce que la toma anterior (aceña 4), se localiza la compuerta/tablacho. Está construida con cuatro bloques de piedra calcarenita: dos colocados en el umbral (de 0,98 cm de anchura) y otros tantos, en los lados, formando las jambas (0,44 m de altura conservada). Los bloques no están ensamblados con ningún tipo de fábrica; sólo se encuentran trabados en los márgenes del cauce o hincados en el fondo del lecho, que está formado por una capa de

\footnotetext{
24 Cuando se facilitó el texto publicado en la Revista Murciana de Antropología (2007), la excavación de esta estructura estaba aún en curso y sólo se había documentado esta parte de la estructura.

25 Esta estructura tiene 1,17 de largo por 0,24 m de anchura máxima conservada.

26 La cota superior de la fábrica se encuentra a 46,99m y su base a 46,36 m.

27 La plasticidad de este lecho ha permitido que quedara en el centro una especie de surco alargado, poco profundo e irregular, que interpretamos como el rastro que dejó el posible roce de los arcaduces con suelo blando de la cubeta, probablemente en un momento cercano a su destrucción.

28 Coordenadas absolutas UTM ED50 30N de la intersección del conducto subterráneo con el muro: x: 661699, y: 4207947.

29 La longitud de los atanores oscila entre 0,31 y 0,34 m. El diámetro interno es de 0,26 m y sus embocaduras presentan refuerzos anulares de sección cuadrada. Están fabricados con arcillas de color amarillo, de textura rugosa poco compacta y quebradiza.
} 

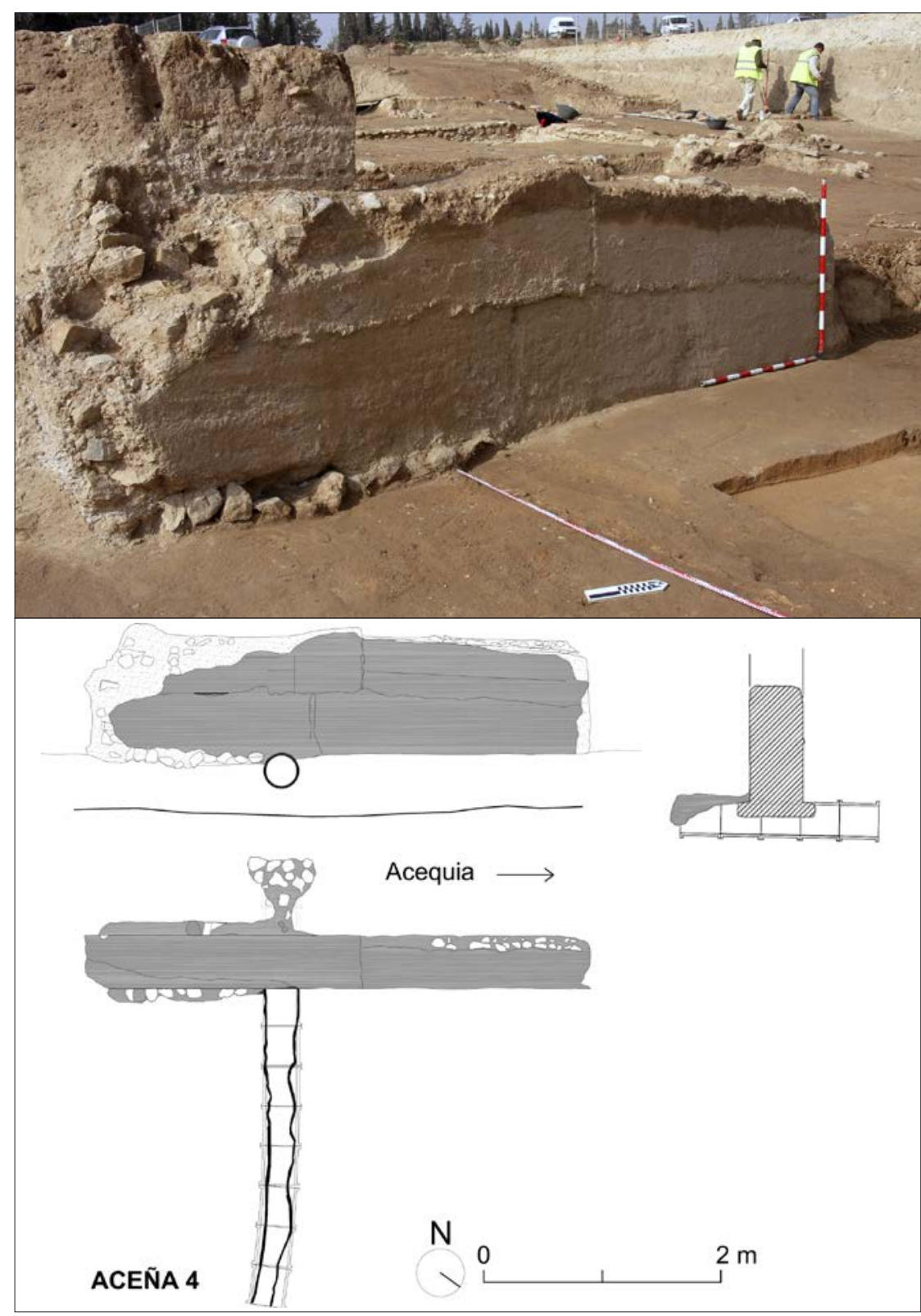

Figura 7. La toma de la aceña 4 está formado por un muro encofrado integrado en el cauce de la acequia y un conducto subterráneo de atanores cerámicos que termina, dentro del cauce, en una embocadura reforzada con mampostería.

arenas, gravas y clastos de diverso tamaño ${ }^{30}$. Aguas arriba del cauce (cara norte), la estructura se encuentra reforzada a ambos lados con bloques irregulares de menor tamaño ${ }^{31}$.

Las tres piezas que forman la compuerta están labradas sólo por dentro, mostrando una ranura de $4 / 5 \mathrm{~cm}$ de ancho por $4 / 5 \mathrm{~cm}$ de profundidad, entalle que formaba la guía donde se insertaba la compuerta o tablacho de madera, quedando el resto de la piedra sin ningún tipo de trabajo.

La estructura de piedra se sitúa en el fondo de un cauce ${ }^{32}$, con trayectoria SO-NE, excavado en un nivel natural de arcilla anaranjada de

30 La estructura carece de material cerámico; sólo se halló en el mismo cauce (aguas arriba) un fragmento de galbo de cerámica esgrafiada.

31 La posición de este refuerzo parece indicarnos la dirección de la corriente. Si el agua era retenida con el tablacho, el lado contrario (aguas abajo) debía soportar mayor presión.

32 Coordenadas absolutas UTM ED50 30N: x: 661702, y: 4207929. El umbral del tablacho se halla a 47,63 m. 
gran espesor que se extiende por toda la zona. Por encima el canal se hallaba totalmente colmatado por diversas capas sedimentarias de relleno integradas por lechos de limos, arenas y cantos, sobre las que finalmente se extendía una capa de tierra de labor anormalmente apelmazada.

\section{LOS ARCADUCES DE SENDA DE GRANADA}

El material cerámico estudiado procede del interior de los respectivos pozos de las aceñas 1, 2 y 3, del nivel de destrucción de ésta y de la toma de la aceña 4, hallándose todas estas estructuras selladas por un potente nivel de limos que amortizó todo el yacimiento a partir del siglo XIII, incluidos los restos de las cajas de las norias.

El registro documentado está formado mayoritariamente por los arcaduces de noria, en menor cuantía por los atanores que forman los conductos subterráneos y, en una proporción casi testimonial, por galbos de otros recipientes.

El arcaduz (qâdûs) es un recipiente cerámico diseñado para contener y transportar agua en las máquinas hidráulicas. Sin embargo, además de esta aplicación práctica, también se conoce su empleo, entre otros usos, como recipiente culinario, higiénico, ornamental o cultual (BAZZANA- DE MEULEMEETER, 2009: 217, 227) ${ }^{33}$.

El arcaduz se podría considerar, pues, una pieza más de la máquina hidráulica elevadora de agua y como tal, artefacto renovable de una máquina, su diseño ha de responder a razones técnicas de eficacia y rendimiento (capacidad, resistencia, durabilidad, etc.) como el resto de elementos que forman el ingenio. Por esta razón podemos considerar que la forma o estructura de su cuerpo obedece, fundamentalmente, a principios prácticos y funcionales como el sistema de colocación en las maromas que conforman la cadena o rosario de arcaduces. Atendiendo a los modelos de arcaduz que se conocen hemos de señalar que la fijación o atadura de éstos siempre ha sido doble, siendo este sistema el más apropiado para evitar la rotación incontrolada del recipiente y la consiguiente pérdida de agua durante la extracción. A pesar de esta uniformidad técnica, la posición que ocupa esta doble ligadura en el recipiente, sin embargo, difiere en unos y otros casos aunque éstos se reducen también a dos modelos básicos: el amarre próximo-distal y el amarre próximo-medial ${ }^{34}$. En el primero, el arcaduz se fija por los extremos del vaso, es decir, por debajo del borde y por la base; mientras que en el segundo, permanece la zona proximal (cuello del recipiente), en tanto que el inferior se encuentra en la zona central del recipiente. A partir de esta doble solución técnica la estructura básica del cuerpo de los arcaduces adopta igualmente dos variantes: la tendencia troncocónica, para los de amarre próximo-distal, y la cilíndrica con diversas variantes en los de sujeción próximo-medial. Los demás aspectos formales de la pieza, aún en recipientes de estructura semejante, ofrecen múltiples terminaciones, siendo la base la parte que aporta uno de los rasgos más característicos. Entre los de cuerpo troncocónico hallamos bases con forma de peana plana, de botón recortado o esférica irregular; entre los de tendencia cilíndrica se documentan dos tipos, el fondo plano o plano-convexo (con

\footnotetext{
33 Bazzana-De Meulemeester (2009: 227) señalan el empleo de pequeños arcaduces (8 cm de diámetro) de menor tamaño de lo habitual (15/20 cm) empleados en los baños o en las abluciones rituales. También se conocen como cacerola o florero/maceta (Bosch y Chichilla, 1987, 498; Bazzana-De Meulemeester, 2009, 217; Fuertes Santos, 2010, 154). Caso excepcional constituye la localización de estas piezas en el interior del pozo negro de algunas letrinas domésticas en Madinat Siyâsa, que se relaciona con la limpieza y recuperación de la materia fecal como abono agrícola (Reklaityte, 2006, 232).

34 Para definir/denominar la posición de los punto de amarre del arcaduz hemos adoptado la terminología anatómica de localización, aceptada en diversas áreas científicas. Según ésta, el eje próximo-distal, o mejor, los extremos proximal y distal que delimitan este eje, son empleados para definir la posición que ocupan los apéndices del cuerpo con respecto a éste. En nuestro caso, consideramos el cuello del recipiente, el extremo proximal de la vasija; en tanto que la base, el pie o el ápice de un vaso se localiza en el extremo distal del mismo. http://es.wikipedia.org/wiki/Terminolog\%C3\%ADa_anat\%C3\%B3mica_de_localizaci\%C3\%B3n\#Eje_pr.C3.B3ximo-distal
} 
o sin pie anular) y el puntiagudo con forma cónica o de ojiva.

En Senda de Granada se documentan ambos modelos de arcaduz y siguiendo este criterio morfológico y funcional hemos distinguido los dos tipos con la siguiente nomenclatura: I, los de amarre próximo-distal y II, los de engarce próximo-medial.

\subsection{Arcaduz de amarre próximo-distal: tipo I, variantes A y B}

Los arcaduces de amarre próximo-distal se localizan mayoritariamente en las aceñas 1 y 2 , y en una proporción muy reducida, también en la 3.

\subsubsection{ARCADUZ TIPO I-A}

Los arcaduces del tipo I-A proceden mayoritariamente de la aceña 1 , de la aceña 3 y del entorno de ésta.
En el interior del pozo de la aceña 1, de un total de 156 fragmentos, se han registrado 6 fragmentos de ápice, que corresponden a un número mínimo de 5 piezas, y se han inventariado 20 fragmentos de borde que podríamos atribuir, sin total certeza, en razón de la morfología de los bordes y la composición de su pasta, a un máximo de 17 recipientes.

Los arcaduces del tipo I-A son recipientes de gran tamaño de cuerpo cónico, con la parte superior de tendencia globular, terminado en un grosero y tosco botón basal irregular. El cuello acentuado termina en una boca ancha exvasada, con borde de sección triangular cóncavo por dentro y reborde externo, siendo variables la anchura de la acanaladura interior - la prominencia de la pestaña externa. Los parámetros morfométricos de este tipo los proporciona un único recipiente recuperado completo (Lám. 1 y Fig. 8): 37,4 cm de altura, $10,7 \mathrm{~cm}$ de boca, $16,7 \mathrm{~cm}$ de diámetro máximo (hombro) y ápice asimétrico (de tendencia

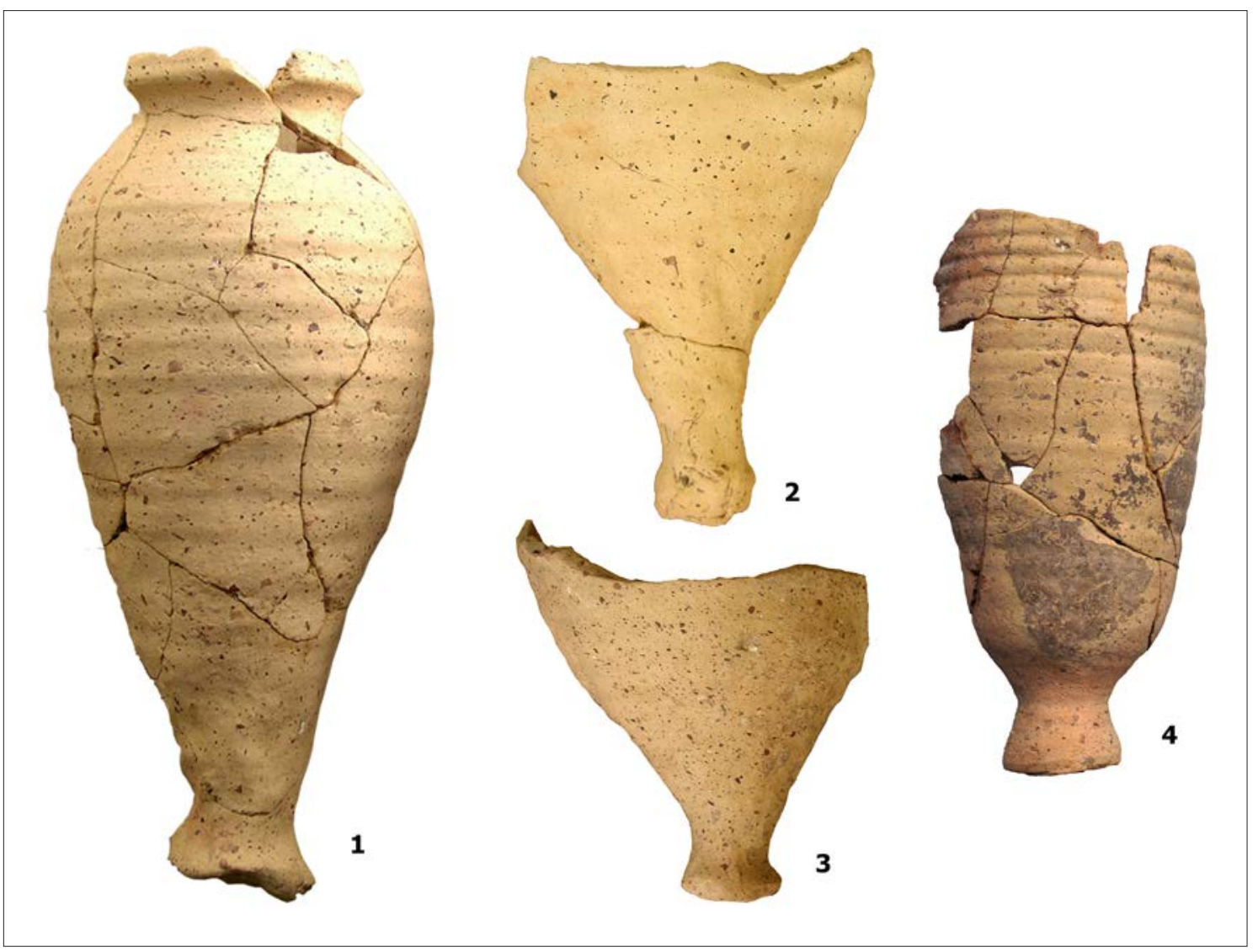

Lám. 1. Arcaduces tipo I de Senda de Granada (Espinardo, Murcia): 1: arcaduz tipo / A, 2: ápice AP2-I A, 3: ápice AP4-IB, 4: AP3-IA 


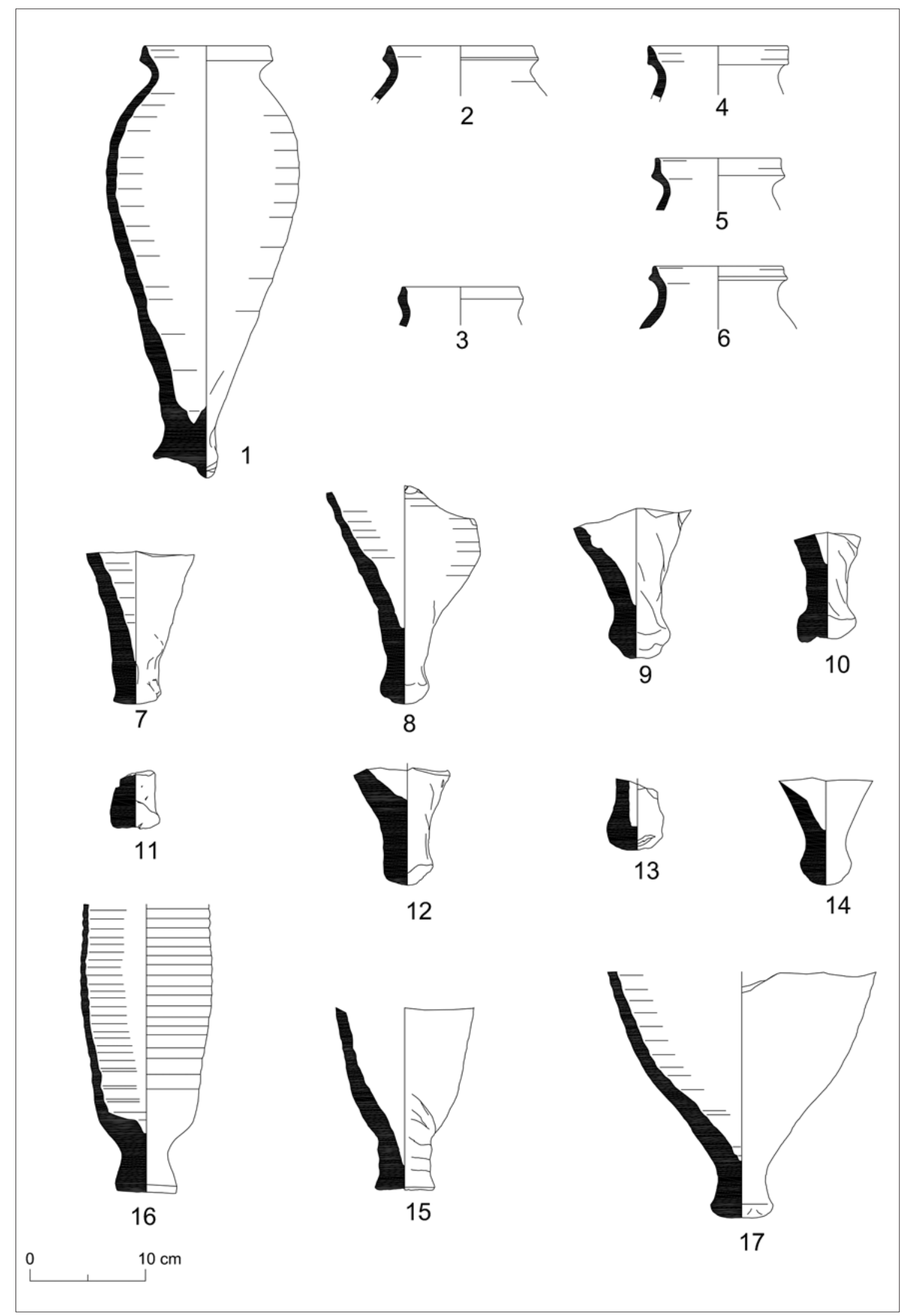

Figura 8. 1-6 arcaduces tipo I A de Senda de Granada (Espinardo, Murcia); abajo, ápices de arcaduz tipos / Ay / B. 
cilíndrica) de 5,6 cm de anchura. El diámetro de la boca de los demás ejemplares estudiados oscila entre un mínimo de $10 \mathrm{~cm}$ y un máximo de $12,35 \mathrm{~cm}$.

La boca y el cuerpo están modelados a torno y la base terminada a mano. Los ápices son de factura muy tosca, de tendencia cilíndrica irregular (AP1-IA) o esférica (AP2-IA) (Lám. 1,1 y 2), con algunos aplastamientos asimétricos y huellas plásticas helicoidales en su unión con el cuerpo. Por dentro se aprecian marcadas estrías de torneado, mientras que por fuera éstas aparecen como suaves ondulaciones.

Las pastas son poco consistentes, con arcillas de tonos claros que varían del amarillo pálido al beige/salmón. La textura es, en ambos casos, homogénea, de aspecto pastoso (sin poros), blanda y de baja densidad. En las pastas amarillentas los desgrasantes, de tamaño medio y fino, son abundantes destacando la filita violácea y los esquistos grises y negros. Las arcillas de tonos beige muestran desgrasantes de tamaño grueso, medio y fino de partículas de color granate, grisáceo y negro, visibles en la superficie externa. La fractura suele ser irregular y sin arista. Equiparables al tipo de pasta II descrito por S. Gutiérrez Lloret (1996, pp. 50-51) $)^{35}$.

En la aceña 3 también se hallaron, junto al tipo II de amarre central y base apuntada mayoritario en esta estructura, un reducido número de piezas del tipo I-A con ápices macizos (5) de forma cilíndrica o de botón esférico ${ }^{36}$.

Esta misma mezcla de tipos de arcaduz se registra también en el nivel externo de destrucción de la propia estructura localizado en la parte meridional de la aceña, que se extiende sobre un antiguo espacio de silos tardorromanos. Aquí, junto a los recipientes de cuerpo globulary los de hombro carenado, hallamos entre los arcaduces tipo I-A, una variante nueva de pie: una especie de peana alta de forma cónica con $5 \mathrm{~cm}$ de diámetro en la base y $4 \mathrm{~cm}$ de altura (AP3-IA) (Fig. 9, 3).

\subsubsection{ARCADUZ TIPO I-B}

En la aceña 2 se registraron 1389 fragmentos de este tipo arcaduz de los cuales el 84,88 $\%$ son galbos informes ${ }^{37}$. Con el porcentaje restante se ha identificado entre un número mínimo cierto de 18 piezas (individualizadas

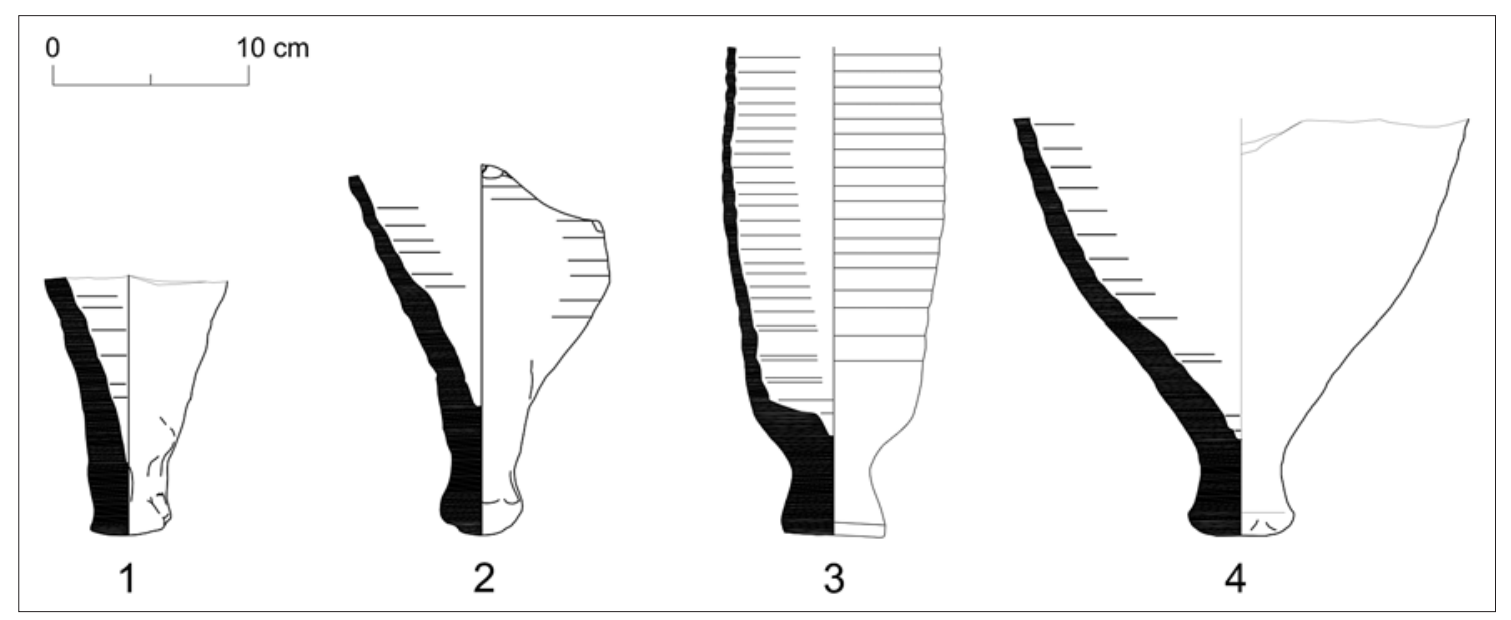

Figura 9. Ápices de arcaduz tipos / A y / B.

35 Como señala la autora, la variedad de pastas obedece seguramente a la composición específica de las arcillas de cada centro productor, cuya caracterización sólo se puede determinar a partir de análisis químicos.

36 La presencia de ambos tipos de arcaduz en la aceña 3, aunque en proporción muy dispar (14/5), nos indica la prolongada vida de esta estructura hidráulica construida a un tiempo que la aceña 1.

37 El elevado número de fragmentos cerámicos (1389) se debe, probablemente, a un proceso de relleno intencionado, durante el que se introdujeron los restos de los recipientes, algunos elementos pétreos e, incluso, trozos de la propia fábrica del pozo. 
por su ápice) y un máximo probable de 140 , si atendemos a la morfología del borde y la composición de su pasta ${ }^{38}$.

Aunque no se ha restituido completamente ninguna pieza, las características técnicas no dejan duda acerca de su similitud con los arcaduces de la aceña 1, pues, desde el punto de vista funcional ambos tipos disponen de un sistema de agarre distal, con cuello acentuado y extremo basal reforzado (Fig. 10). No obstante, estos ejemplares se diferencian

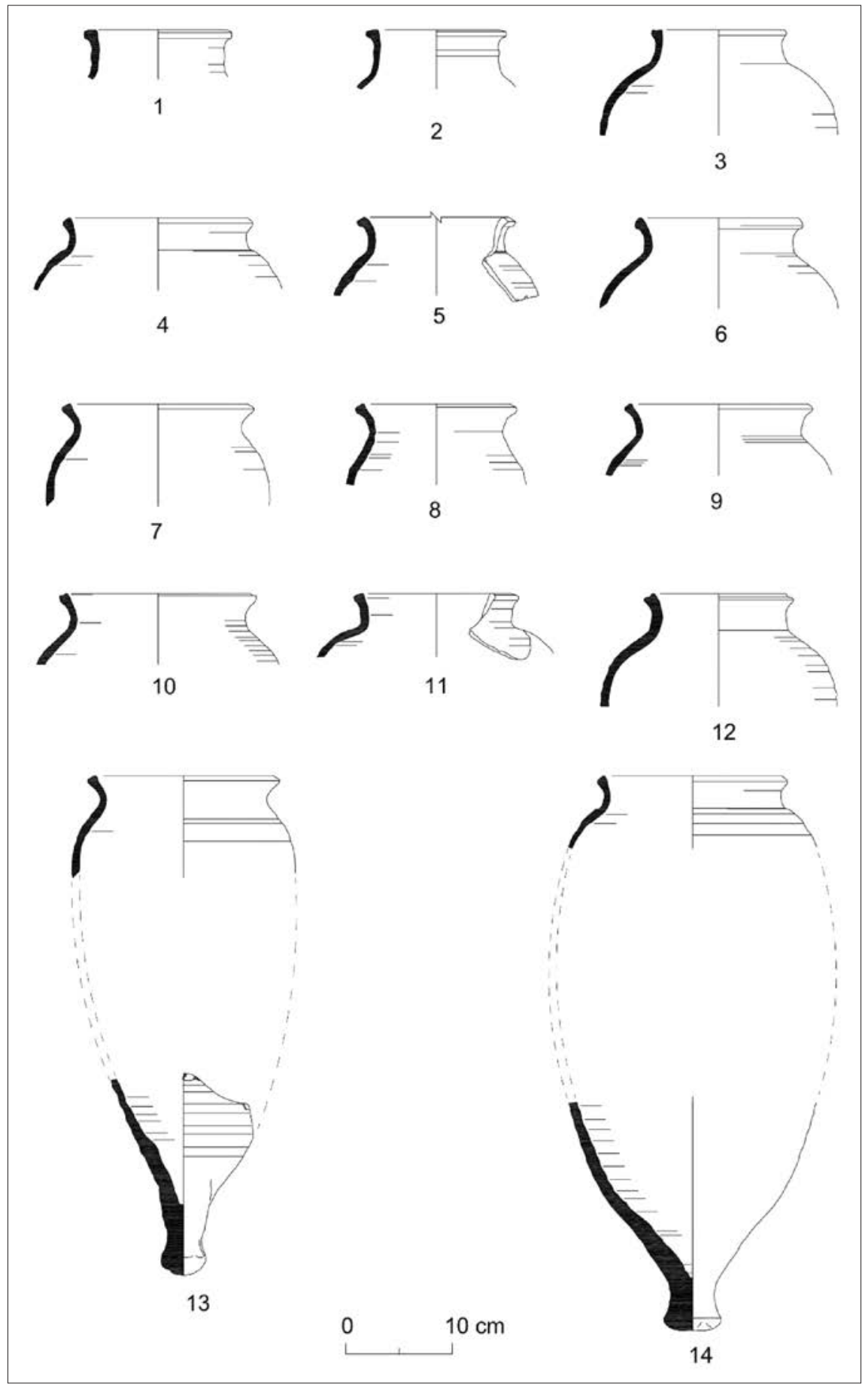

Figura 10. Arcaduces tipo I B de Senda de Granada (Espinardo, Murcia).

38 La producción poco cuidada de estos elementos permite observar en las bordes pequeñas diferencias morfológicas, aún perteneciendo todos ellos a un mismo tipo. Esta variabilidad morfológica junto a la coloración de la pasta, ha servido para proponer este cómputo. 
de aquellos por su mayor tamaño, el tipo de borde y la amplitud del hombro.

En primer lugar las embocaduras aumentan de diámetro alcanzando medias de 13 y 16 $\mathrm{cm}$, incrementándose en la misma proporción la altura del cuello superando los $3 \mathrm{~cm}$. La anchura máxima del cuerpo, que en todos los casos estudiados superan los $20 \mathrm{~cm}$ de diámetro, alcanza una media de $22 \mathrm{~cm}$ y máximos de $23,29 \mathrm{~cm}^{39}$.

Al mismo tiempo el borde ofrece mayor variabilidad en cuando a su orientación y la forma del labio. Los bordes verticales con labio engrosado de sección cuadrada (Fig. 10, $1-3)$, son poco numerosos mientras que los exvasados triangulares son mayoritarios (Fig. 10, 4-12). Éstos aportan labios muy diferentes, que van desde los sencillos redondeados (Fig. 10, 4-9) hasta los engrosados de sección triangular que, a su vez, pueden presentar un ligero entalle por dentro o una acanaladura superior formando una especie de labio bífido (Fig. 10, 10-12).

Los ápices macizos modelados a mano presentan tres variantes. Los de tendencia esférica en forma de botón irregular (AP21B) (de 4 o $5 \mathrm{~cm}$ de diámetro y entre $4,5 \mathrm{y}$ $7,3 \mathrm{~cm}$ de longitud), resultado de aplicar una pella de barro tras cortar la pieza una vez terminado el torneado, que suele dejar huellas helicoidales en el tronco macizo de unión con el vaso (Fig. 9, 2), son los más frecuentes y característicos. Otro tipo lo representa un caso único de contera termina en una especie de peana plana de perfil redondeado (AP4-1B) de $5 \mathrm{~cm}$ de diámetro (Fig. 9, 4; Lám. 1, 3). Y finalmente se documenta un tercer mode- lo de forma cilíndrica (AP1-1B, equiparable al AP1-1A) (con dos casos) de $4 \mathrm{~cm}$ de anchura por $3 / 4 \mathrm{~cm}$ de altura ${ }^{40}$ (Fig. 8, 7, 11).

\subsection{Arcaduz de amarre próximo-medial (tipo II)}

Los arcaduces de amarre próximo-medial se documentan en el interior del pozo de la aceña $3(2189,2116)$ y junto a la embocadura de la toma de la aceña $4^{41}$.

En la aceña 3 se han registrado 796 fragmentos, de los cuales el 83,42\% son elementos informes. Los 16 ápices documentados ofrecen un número mínimo de 14 piezas. Los bordes diferenciados entre sí por su morfología y su pasta, permitiría considerar la existencia probable de 75 recipientes. Estos arcaduces tienen cuerpo cilíndrico, borde vuelto y base puntiaguda con perfil en ojiva, sin pie (Lám. 2 y Fig.11).

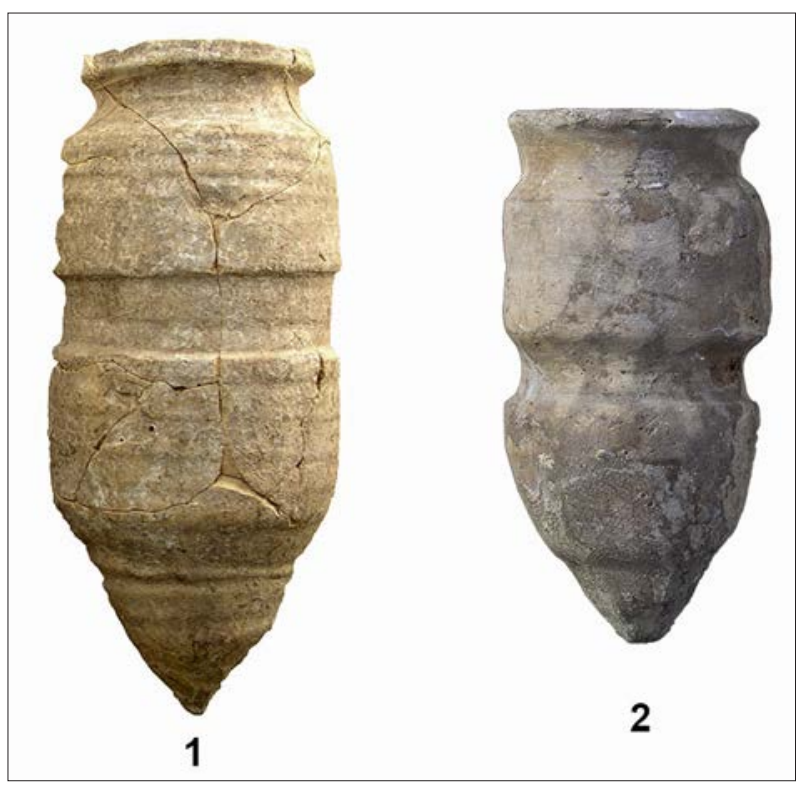

Lámina 2. Arcaduces tipo // de Senda de Granada (Espinar, Murcia).

39 No se ha conservado completo ni se ha podido reconstruir ningún recipiente del tipo I-B, por lo que se desconoce la altura total de la pieza. A partir del modelo completo del tipo I-A y otros fragmentos, se ha comprobado que la altura de la pieza equivale a 2,23 veces la anchura del cuerpo, de modo que si aplicamos dicha ratio los arcaduces del tipo I-B alcanzarían una altura media teórica de $46 \mathrm{~cm}$.

40 No obstante, hemos de señalar que el reducido número de ejemplares de la muestra no permite establecer más que ofrecer una tipología provisional. No podemos descartar que esta variedad de ápices se deba a un proceso de ejecución descuidado de un único prototipo, el ápice con botón esférico modelado a mano.

41 Junto a la embocadura de la toma situada dentro de la acequia, se documentó un único fragmento de base apuntada y varios galbos informes de arcaduz del tipo II. Estos fragmentos se depositaron, probablemente de forma accidental inmediatamente antes de su inutilización definitiva por acumulación de légamo. 


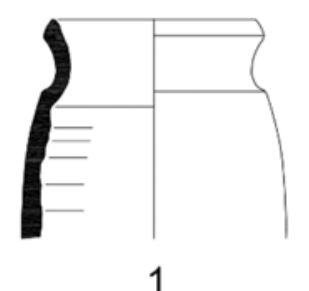

1

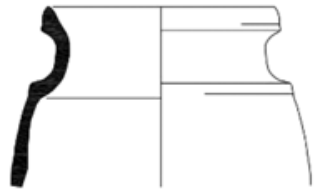

2

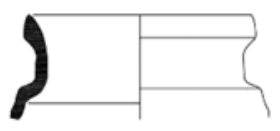

3

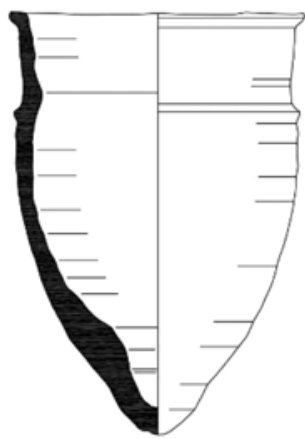

10

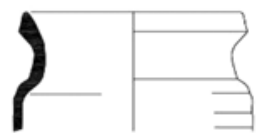

6
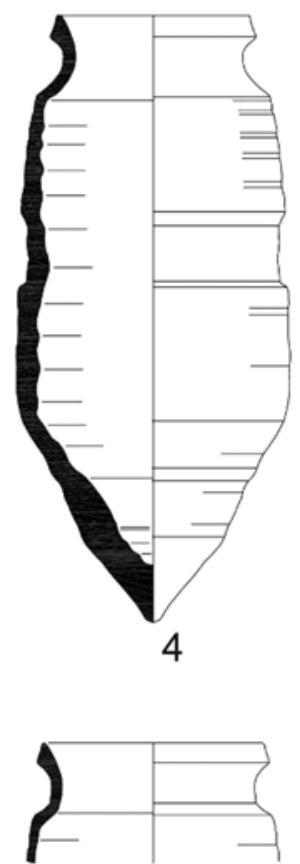

5

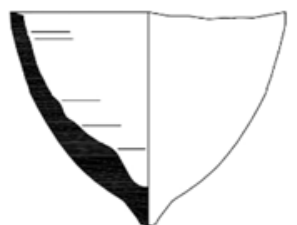

11 $10 \mathrm{~cm}$
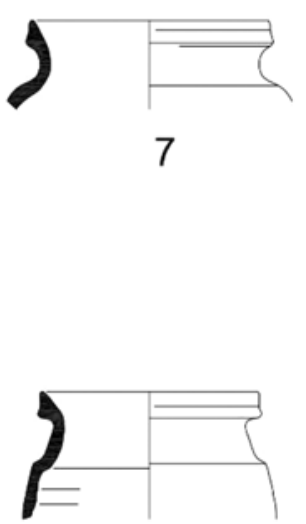

8

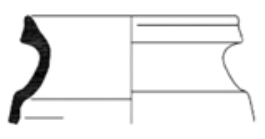

9

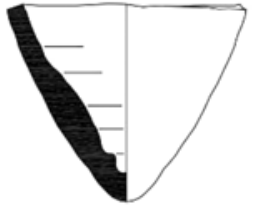

12

Figura 11. Arcaduces tipo I/ de Senda de Granada (Espinardo, Murcia).

En el orden técnico presentan como novedad dos marcados estrangulamientos, situados en el centro del cuerpo y en la parte alta de la pieza debajo del borde (Fig. 11, 4). La escotadura superior de perfil curvo forma con el hombro una carena muy característica que facilita la identificación del borde de este tipo arcaduz. La hendedura central, delimitada por sendas aristas biseladas, tiene entre 4 y $5 \mathrm{~cm}$ de altura, es recta y poco profunda. Los bordes son exvasados de labio sencillo redondeado o engrosado de sección triangular (Fig. 11, 1-6), presentando, en este caso, la arista inferior más o menos acentuada y una leve acanaladura por dentro (Fig. 11, 7-9). El cuerpo suele ser cilíndrico aunque también se 
registran perfiles de tendencia globular. El diámetro de la boca suele tener $11 \mathrm{~cm}$ de media, aunque oscila entre un rango de 10 y $12 \mathrm{~cm}$. En este mismo orden, los demás parámetros del vaso se reducen ligeramente respecto del tipo I: $32,12 \mathrm{~cm}$ de altura y $14,5 \mathrm{~cm}$ de anchura máxima del cuerpo.

Estos recipientes están completamente modelados a torno, con un torneado y factura más cuidada. Su pasta, también más depurada, es de tonos amarillento/marrón claro y su textura homogénea; el desgrasante, fino y medio, está compuesto por filitas granates, esquistos grises y partículas negras/blancas y la mejor cocción ofrece fracturas regulares rectas.

\section{LOS ARCADUCES EN AL-ANDALUS: DIS- TRIBUCIÓN REGIONAL DE LOS TIPOS}

El estudio tipológico de los arcaduces andalusíes arranca en la década de los setenta del siglo pasado cuando se incluyen en el Ensayo de sistematización de la cerámica árabe en Mallorca elaborado por G. Rosselló Bordoy (1978). A mediados de los ochenta J. Navarro Palazón (1986) aborda en la Cerámica islámica en Murcia una nueva clasificación siguiendo criterios funcionales (sin abandonar criterios morfológicos, técnicos o estéticos), en la que incluye este tipo de recipientes en el grupo de utensilios de uso complementario. Aun tiempo se producen en el sureste peninsular (Tudmirr) los hallazgos de los modelos más antiguos, primero en el Bajo Segura (Cabezo del Molino en Rojales, Alicante), hecho que permite a S. Gutiérrez Lloret (1986) remontar la presencia de estos artefactos en al-Andalus a los siglos VIII/IX y, luego, en Baŷŷana (Pechina, Almería) (ACIEN y MARTínEZ, 1989). En tanto que la excavación de una noria árabe en Oliva (Valencia), permitió a sus excavadores A. Bazzana, S. Climent e Y. Montmessin (1987), plantear la primera tabla crono-tipológica de los arcaduces valencianos (ss. X-XIII/XIV).

Desde entonces se han ido produciendo numerosos hallazgos tanto en estructuras hidráulicas como en contextos domésticos, hornos o vertederos, registrándose todo el espectro crono-tipológico (siglo IX al XIII). La mayor parte de las piezas documentadas son elementos funcionalmente descontextualizados y con escasa representación numérica, que testimonian la existencia de antiguas maquinas hidráulicas de carácter agrícola en espacios irrigados, o doméstico/cultual en contextos urbanos, cuya datación en muchos casos no se puede establecer con precisión, por lo que se ha debido recurrir, en cada caso, a los paralelos más cercanos. Sólo los grandes conjuntos procedentes de aceñas o norias como la mencionada de Les Jovades (Oliva, Valencia) ${ }^{42}$, La Ollita (Niebla) (BENABAT y PÉREZ, 2009) y Saltés (BAZZANA y BEDIA, 2009) en Huelva, el conjunto de Cercadilla (Córdoba) (FUERTES SANTOS, 2010) O, nuestro caso, en Senda de Granada, ofrecen más posibilidades de estudio ${ }^{43}$.

En Senda de Granada, además del análisis crono-tipológico de los arcaduces, hemos abordado su estudio desde el punto de vista morfo-técnico y funcional, al tiempo que analizamos si alguno de los rasgos formales que ostentan estas piezas, como la posición de los puntos de engarce de los recipientes en la rueda hidráulica, se pueden considerar indicadores cronológicos de su evolución.

En este sentido hemos constatado que, tanto en Senda de Granada como en el resto de al-Andalus, el arcaduz adopta una doble solución técnica respecto a su sujeción: el amarre próximo-distal y el próximo-medial;

\footnotetext{
42 El prolongado uso de las aceñas con las consiguientes labores mantenimiento (limpieza del pozo, reparaciones, etc.) o la misma amortización intencionada final, son procesos que suelen "alterar" la deposición estratigráfica. En el mejor de los casos se localizan restos estratificados adheridos a las paredes del pozo, como sucede en Les Jovades, donde aparecer asociados otros materiales cerámicos más fáciles de datar.

43 El hallazgo de un conjunto de cuatro aceñas como el de Senda de Granada es inusual, máxime cuando aportan un volumen de material significativo.
} 
aspecto que determina o va ligado, a su vez, a la estructura básica del cuerpo: la troncocónica invertida, para los de amarre próximo-distal, y la cilíndrica con diversas variantes, en los de sujeción próximo-medial, adoptando el resto de aspectos formales en cada modelo múltiples terminaciones. Modelos a los que habría que añadir el caso excepcional y singular de los arcaduces emirales de Mérida que presenta un amarre triple (proximal-medial-distal) en un cuerpo cilíndrico (ALBA y FEIJOO, 2003: Fig. 13).

Desde el punto de vista cronológico apreciamos que la diferente posición de los engar- ces no implica distinta datación (Tabla 1). Si revisamos los arcaduces andalusíes mejor fechados se constata que los arcaduces de amarre próximo-distal y los que emplean el sistema próximo-medial conviven un largo periodo de tiempo que se extiende entre los siglos IX y XI o, quizás, más.

Así mismo, si atendemos a su distribución espacial, constatamos que ambos sistemas no coexisten en el mismo espacio geográfico sino que ocupan zonas distintas excluyentes ${ }^{44}$ (Fig. 12). Los de amarre próximo-distal se focalizan en el SE peninsular, concretamente

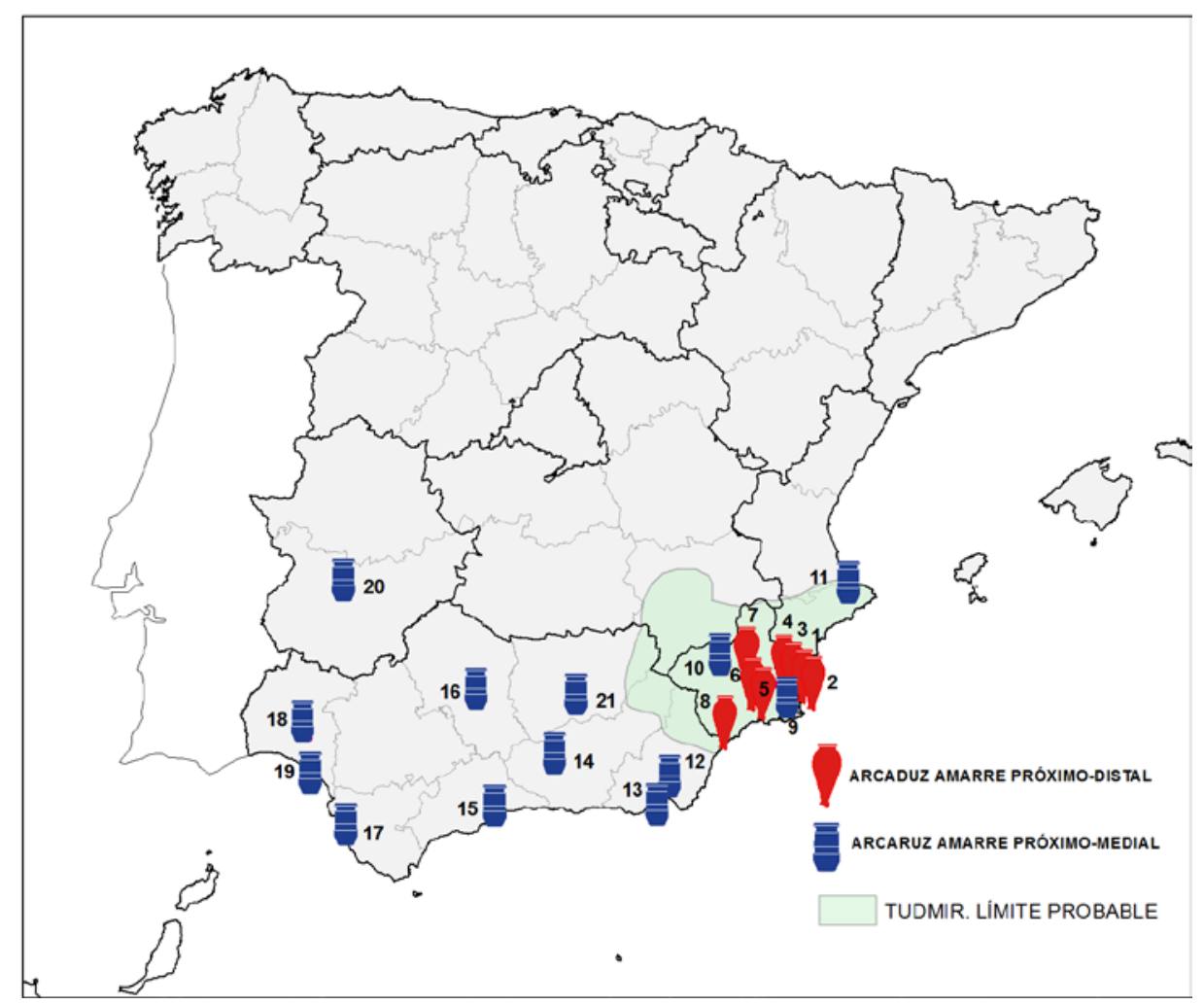

Figura 12. Dispersión tipológica de arcaduces en al-Andalus meridional. 1, Cabezo del Molino (Rojales, Alicante). 2, La Rábita (Guardamar, Alicante). 3, Castillo de la Sierra (Callosa, Alicante). 4, Cabecicos Verdes (Orihuela, Alicante). 5, M. Mursiya (Murcia). 6, Senda de Granada (Murcia). 7, M. Siyâsa (Cieza, Murcia). 8, Glorieta S. Vicente (Lorca, Murcia). 9, Pocico II (Murcia), 10, Villa Vieja (Calasparra, Murcia). 11, Oliva (Valencia). 12, Bâŷyana (Pechina, Almería). 13, Almería. 14, M. Ilbira (Atarfe, Granada). 15, Málaga. 16, M. al-Zahra (Córdoba). 17, M. Yazirat Qadis (Cádiz). 18, Niebla (Huelva). 19, Saltés. 20, Mérida. 21, Marroquíes Bajos (Jaén).

\footnotetext{
44 S. Gutiérrez, ya advierte la existencia de "diferencias regionales en las evoluciones tipológicas del mobiliario cerámico" con la consiguiente posibilidad de datación en cada zona: "las diferencias tipológicas evolutivas existentes entre yacimientos: parecen ya indicar por sí mismas las, por otro lado lógicas, diferencias regionales en las evoluciones tipológicas y contribuyen a desterrar definitivamente el tópico funcionalista de su inmutabilidad morfológica y la subsiguiente imposibilidad de datación" (1996, 8).
} 


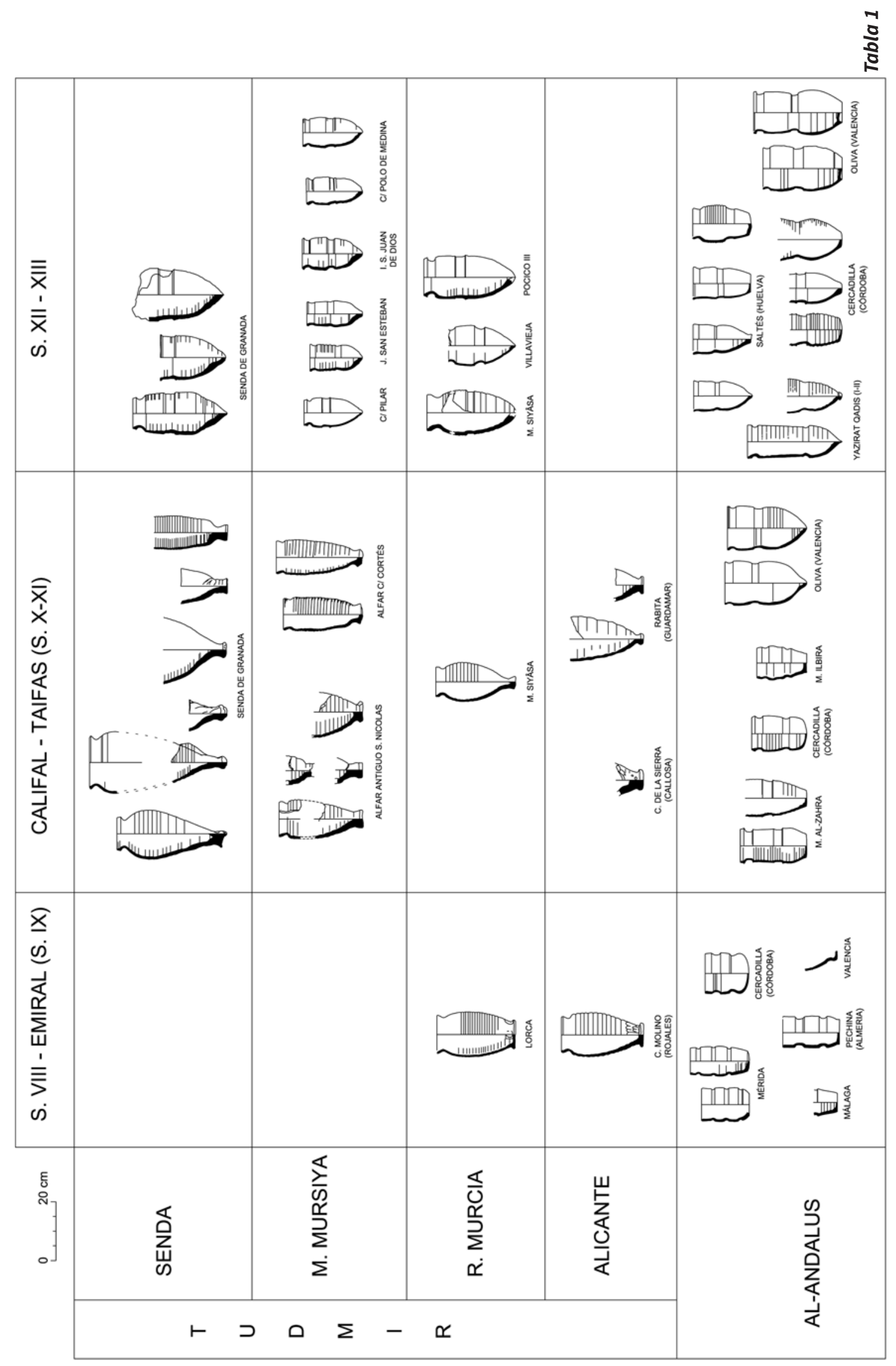


en la vega media y baja del río Segura (Cora de Tudmirr) ${ }^{45}$, en tanto que los de amarre próximo-medial se expanden desde Baŷỹana (Almería) hacia resto de al-Andalus.

A su vez, se observa que el desarrollo evolutivo de cada modelo, a pesar de su diferente distribución espacial, tampoco fue uniforme, apreciándose notables diferencias entre individuos sincrónicos formalmente semejantes ${ }^{46}$, aunque todos exhiben fondo plano (mayoritariamente sin pie) hasta que hacia el siglo XII el modelo quedó definitivamente estandarizado en todo al-Andalus, prevaleciendo los de amarre próximo-medial y base apuntada ${ }^{47}$. Fecha en la que también se constata en Murcia el remplazo de los artefactos de amarre próximo-distal por los de sujeción próximomedial ${ }^{48}$; cambio que resulta llamativo porque no parece consecuencia de un determinado proceso evolutivo, sino la mera sustitución de un modelo por otro ${ }^{49}$.

Probablemente la transición de uno a otro modelo no se produjo sólo por razones técnicas. La distribución espacial de cada modelo ofrece una nueva perspectiva en el análisis y nos induce a considerar otros motivos, quizás su posible vinculación a determinados grupos artesanales localizados en áreas diferenciadas ${ }^{50}$.

Sabemos que los arcaduces de fijación próximo-distal terminaron por desaparecer en al-Andalus a finales del siglo XI (Tabla 2). Sin embargo, estudios etnográficos recientes ofrecen ejemplos, en otras regiones mediterráneas (Lám. 3), del empleo del mismo sistema de amarre en un tipo de arcaduz muy parecido, provisto, incluso, de un ápice en el extremo basal del recipiente (SCHIøLER, 2012; BAZZANA-DE MEULEMEESTER, 2009, p. 218, fig. 99; GUTIÉRREZ LLORET, 1996b: 12, Láms. 3-4) ${ }^{51}$. La coexistencia actual de ambos modelos pone de manifiesto que su eficacia técnica es, cuando menos, semejante, razón por la cual habría que descartar las exclusivas razones técnicas como motivo de su desaparición en época islámica.

Estos indicios parecen indicar, por el contrario, que el empleo de uno u otro modelo responde, desde época temprana (ss. VIII-IX), a una arraigada tradición de carácter agrícolaartesanal vinculada, probablemente, a un

45 Arcaduces semejantes de amarre próximo-distal, aunque de morfología dispar, en el ámbito peninsular encontramos un tipo parecido en Almadén (Jaén) (BOSCH y CHICHILLA, 1987), en las islas Baleares en Son Mosson (Mallorca) (ROSELLÓ BORDOY, 1978) y en mediterráneo central en Palermo (Sicilia) (ARCIFA, 1997 y 2010).

46 La tradición gremial local de alfareros, carpinteros y cordeleros también pudo influir en la multiplicidad de variantes constatadas.

47 Se aduce con frecuencia que los cambios tecnológicos en este tipo de recipiente obedecen a la búsqueda de soluciones técnicas para resolver la dificultad de mantener, sin que se mueva, el arcaduz debido al movimiento vertical del sistema y al riesgo de desplazamiento lateral con posibilidad de tropezar contra las paredes el pozo. La existencia de estos accidentes relacionados con los arcaduces (torsión, choque y rotura) la expresa Ibn al-'Awwâm, para lo que recomienda perforar la base de los recipientes (III, 2, p. 146-147)

48 Los modelos de fijación próximo-medial ofrecen una dispersión uniforme tanto en la capital murciana (Madinat Musiya) -calle del Pilar (Navarro Palazón, 1986, 259) y Jardín de San Esteban, Polo de Medina (Pozo Martínez, 1991, 93, fgs. 37-38) (ss. XII-XIII) o Iglesia de San Juan de Dios (segunda mitad del s. XIII)- como en el resto de la región, también en otros centros urbanos como Madinat Siyâsa (Cieza) (Navarro y Jiménez, 2003, 112, fig. 3.6) o en el medio rural, caso de Senda de Granada, la alquería Pocico III (Murcia) (Agradecemos a Clemente García la información relativa al arcaduz documentado en dicha alquería y el dibujo del mismo) o el despoblado de Villa Vieja (Calasparra) (Pozo Martínez, 1989).

49 No podríamos aducir razones tecnológicas para explicar este fenómeno pues en al-Andalus ambos sistemas de fijación llevaban conviviendo ininterrumpidamente trescientos años (SS. IX-XI). Si fuera así cabe interrogarse ¿por qué en Madinat Mursiya se siguió fabricando hasta el siglo XII un tipo de arcaduz que finalmente resultaría tecnológicamente inferior respecto del otro modelo andalusí? Y, en sentido contrario, ¿por qué no encontramos los supuestos modelos precedentes -es decir, los de amarre próximo-distal- allá donde localizamos desde fecha muy temprana los arcaduces supuestamente más evolucionados de sujeción próximo-medial? En todo caso podríamos considerar una posible transferencia tecnológica en sentido contrario: la base fusiforme o apuntada (propia de los recipientes de amarre próximo-distal) que comenzaron a exhibir, hacia el s. XI, los arcaduces con escotadura central, abandonando la base plana con o sin perforación. Probablemente la gran resistencia hidrodinámica que ejerce la base plana de los recipientes, favorecería la transición hacia la terminación fusiforme más eficaz.

50 El aspecto étnico ya ha sido expuesto por otros autores en relación al origen o tipo de aceña (Caro Baroja, 1983,388).

51 Arcaduces de fijación próximo-distal, técnicamente semejantes a los modelos tudmiries, han sido recientemente documentados por Thorkild Schiøler en una aceña en Luxor (Egipto) http://www.kattler.dk/schiolers/uk/detaljer.html (fig. 116), con arcaduces muy parecidos al ejemplo propuesto, sólo por su similitud formal, por S. Gutiérrez Lloret (1996b, 12), y por Bazzana y De Meulemeester (2009, p. 218, fig. 99 Foto de A. Rollet) en Kairouan (Túnez). 


\begin{tabular}{|c|c|c|c|c|c|c|}
\hline \multirow[b]{2}{*}{$\begin{array}{l}\text { TIPO DE } \\
\text { FIJACIÓN }\end{array}$} & \multirow[b]{2}{*}{ ÁREA } & \multicolumn{5}{|l|}{ DATACIÓN } \\
\hline & & EMIRAL (IX) & CALIFAL $(X)$ & TAIFA (XI) & XII & ALMOHADE (XII-XIII) \\
\hline \multirow[t]{2}{*}{$\begin{array}{l}\text { PRÓXIMO- } \\
\text { DISTAL }\end{array}$} & TUDMĪR & $\begin{array}{l}\text { C. Del Molino (Ali) } \\
\text { Glorieta S. Vicente } \\
\text { (Lor) }\end{array}$ & $\begin{array}{l}\text { Ant. Alfar S. Nicolás (Mur) } \\
\text { Alfar C/ Cortés (Mur) } \\
\text { Senda de Granada (Mur) } \\
\text { M. Siyâsa (Mur) } \\
\text { Lorca (Mur) } \\
\text { Rábita Guardamar (Ali) }\end{array}$ & $\begin{array}{l}\text { Senda de } \\
\text { Granada } \\
\text { (Mur) }\end{array}$ & & \\
\hline & AL-ANDALUS & & & & & \\
\hline \multirow{2}{*}{$\begin{array}{l}\text { PRÓXIMO- } \\
\text { MEDIAL }\end{array}$} & TUDMĪR & & & & $\begin{array}{l}\text { C/ del Pilar } \\
\text { (Mur) } \\
\text { Senda de } \\
\text { Granada } \\
\text { (Mur) }\end{array}$ & $\begin{array}{l}\text { Senda de Granada (Mur) } \\
\text { C. Polo de Medina (Mur) } \\
\text { S. Juan de Dios (Mur) } \\
\text { San Esteban (Mur) } \\
\text { M. Siyâsa (Cie-Mur) } \\
\text { Villavieja (Cal-Mur) }\end{array}$ \\
\hline & AL-ANDALUS & $\begin{array}{l}\text { Baŷŷana Pechina } \\
\text { (Alm) } \\
\text { Cercadilla (Cor) } \\
\text { Málaga } \\
\text { Mérida }\end{array}$ & $\begin{array}{l}\text { Noria Oliva (Val) } \\
\text { M. al-Zahra (Cor) } \\
\text { M. Ilbira (Gra) }\end{array}$ & $\begin{array}{l}\text { Noria Oliva } \\
\text { (Val) } \\
\text { La Ollita } \\
\text { (Huel) }\end{array}$ & $\begin{array}{l}\text { Noria Oliva } \\
\text { (Val) } \\
\text { Yazirat Qadis } \\
\text { (Cádiz) } \\
\text { La Ollita } \\
\text { (Huel) }\end{array}$ & $\begin{array}{l}\text { Isla de Saltés (Huel) } \\
\text { Noria Oliva (Val) }\end{array}$ \\
\hline
\end{tabular}

Tabla 2. Tabla de dispersión morfo-técnica de los arcaduces en al-Andalus.
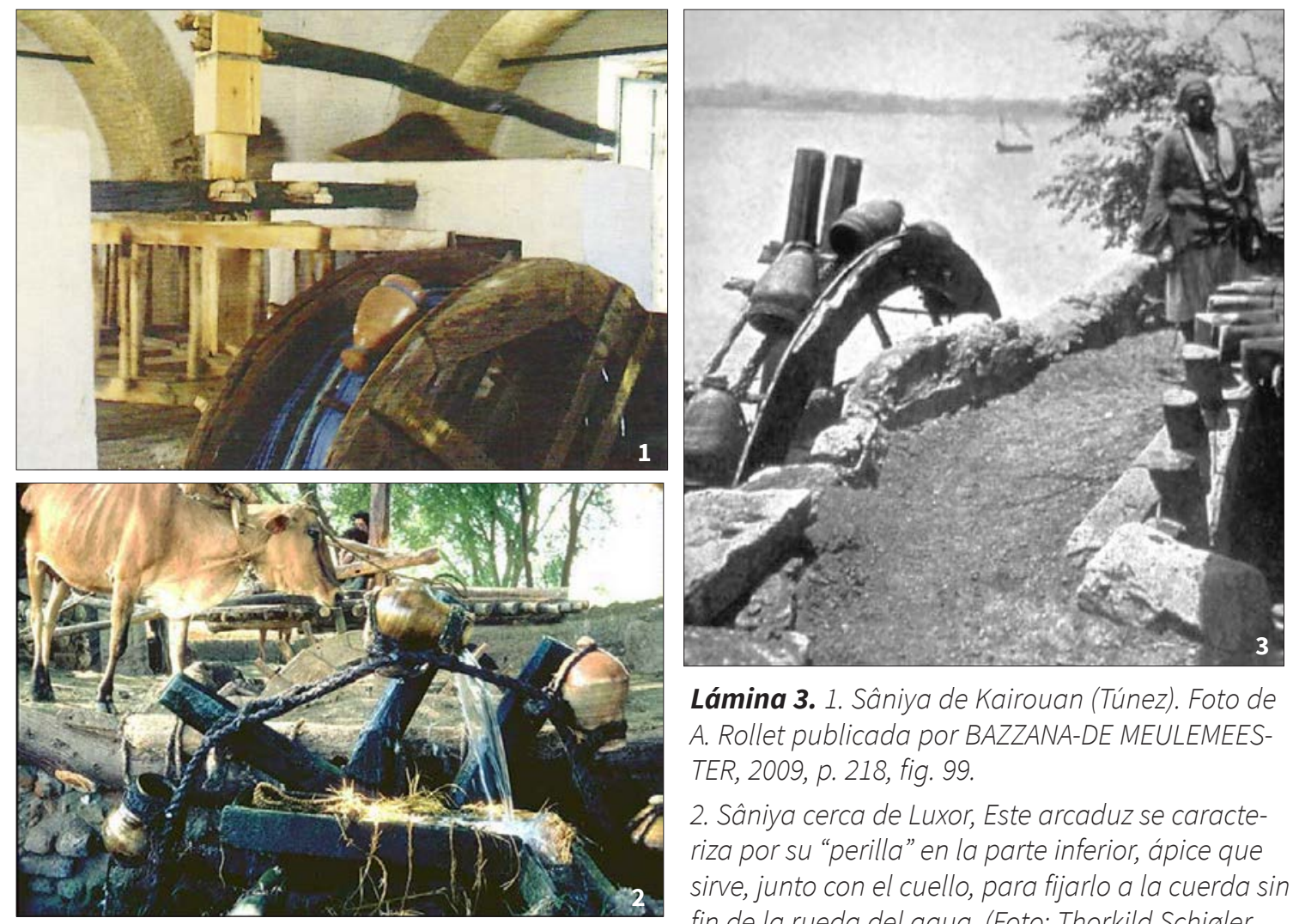

Lámina 3. 1. Sâniya de Kairouan (Túnez). Foto de A. Rollet publicada por BAZZANA-DE MEULEMEESTER, 2009, p. 218, fig. 99.

2. Sâniya cerca de Luxor, Este arcaduz se caracteriza por su "perilla" en la parte inferior, ápice que sirve, junto con el cuello, para fijarlo a la cuerda sin fin de la rueda del agua. (Foto: Thorkild Schiøler, http://www.kattler.dk/schiolers/uk/116.html.

3. Sâniya a orillas del río Nilo (Egipto), Foto de BOYER; fuente: Las razas humanas, dirigida por $P$. BOSCH GIMPERA, Vol. II, p. 193, Publicaciones del Instituto Gallach de Librería y Ediciones, Barcelona, 2 vols., 1928. (Gutiérrez LLoret, 1996, lám. II). 
determinado grupo de población ${ }^{52}$ (GLICK, 1999: 219 y siguientes) que, en el caso de Tudmìr, como refiere al-cUdrī, podríamos relacionar con el asentamiento ŷund de Egipto ${ }^{53}$ (GUTIÉRREZ LLORET, 2013: 269) (Lám. 3, 3). Así pues, podríamos considerar a los arcaduces indicadores útiles, no sólo para delimitar áreas geográficas de dispersión, sino también, como señala S. Gutiérrez, como "testimonio de la temprana introducción [en el Bajo Segura], quizá no generalizada, de una técnica agrícola compleja, que forma parte de un conocimiento agrario que viene evidentemente importado" (GUTIÉRREZ LLORET, 2013: 268).
Si consideramos, pues, que resulta poco probable que los arcaduces de amarre próximo-medial surgieran en Murcia de una mejora técnica promovida por los propios artesanos locales (del medio y bajo Segura), habríamos de plantearnos que la innovación tecnológica hubo de llegar de la mano de población foránea, atraída, quizás, por la estabilidad política y pujanza económica que había alcanzado Murcia o bien como consecuencia de las guerras de taifas externas, a lo largo del s. XI.

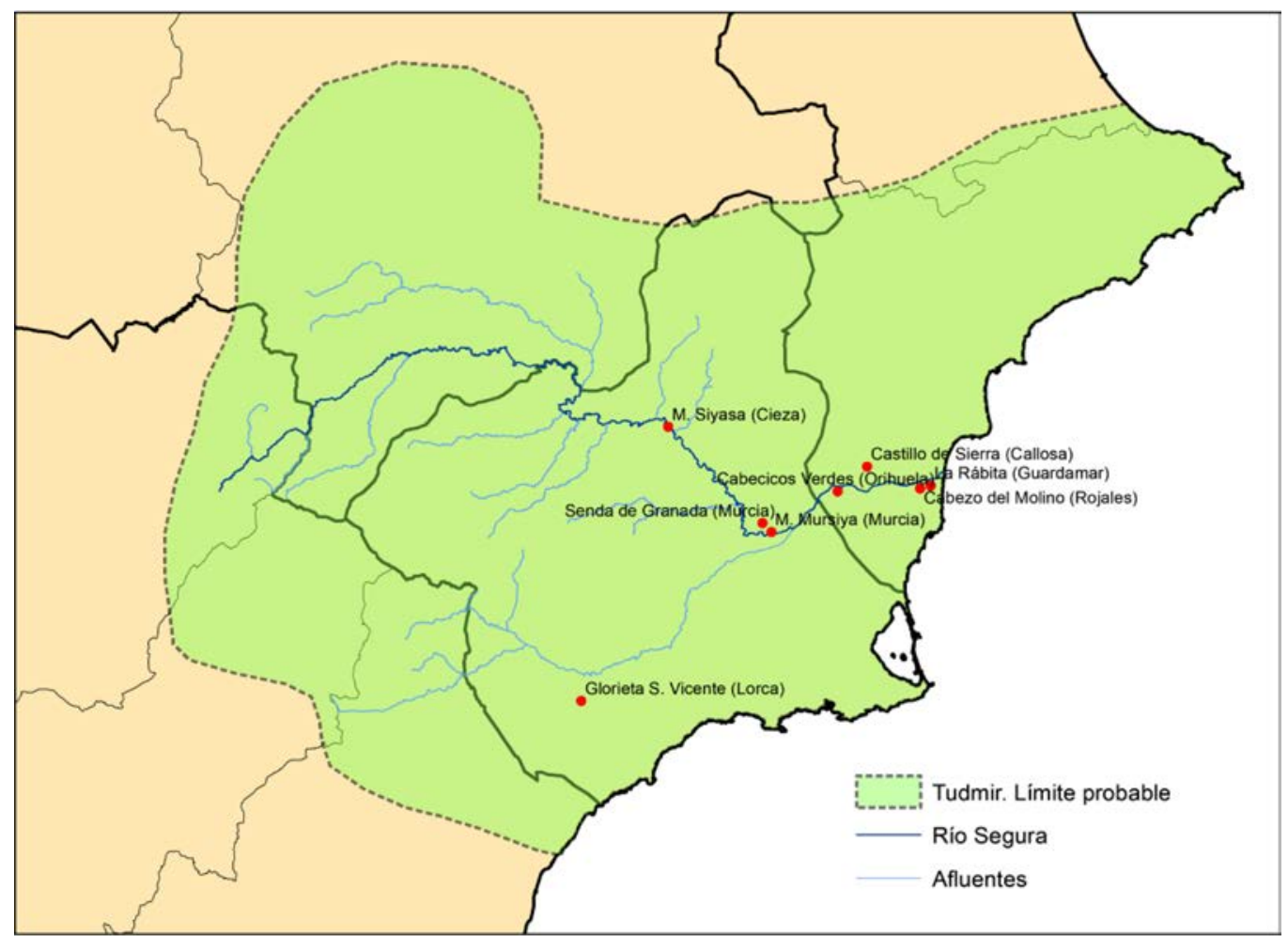

Figura 13. Dispersión de los arcaduces de amarre próximo-distal en la Cora de Tudmir.

52 Como señala T. F. Glick la organización artesanal tradicional en esta época muestra una estructura interna inflexible con objeto de mantener intactas y sin cambios la tecnología probada del gremio, actitud -considerada por los antropólogos como resistente, si no hostil, a la innovación tecnológica-. Esta tendencia inmovilista sólo era vencida, en ocasiones, bien por la creación de un mercado que demandaba esta nueva tecnología (hecho que no sucedía en Madinat Mursiya), o bien por el flujo de artesanos foráneos portadores de aquella práctica distinta. Migración que podía verse incentivada por el desarrollo y la atracción económica que ejercían algunas zonas, debido a las convulsiones sociales o, incluso, por el impulso del propio poder estatal.

53 "Se aposentó en ella [Tudmīr] el ejército de Misr,..." (Al-cuḍī, p. 2) Al-cUḍī (Molina, 1972, pp. 1, 43). Como pone de relieve Sonia Gutiérrez (2013), las fuentes documentales no señalan, por el contrario, el asentamiento de grupos bereberes en la zona estudiada, hecho que "obliga a tomar en consideración las eventuales implicaciones agrícolas,...que pudo tener el asentamiento ŷundí [egipicio] en las alquerías del Bajo Segura”. 


\section{LOS ARCADUCES DE AMARRE PRÓXI- MO-DISTAL TUDMIRÍES}

\subsection{Antecedentes históricos: recipientes cerámicos y mecánica hidráulica}

El extenso registro cerámico altomedieval de la península Ibérica, carece de cualquier tipo de recipiente que podamos relacionar con los ingenios mecánicos hidráulicos que mencionan las fuentes hispanas de la época (rota y austra), especialmente Isidoro de SeviIla (Etym. 20.15.1) ${ }^{54}$. Los cangilones o arcaduces como tales no se detectan en las series cerámicas hasta época emiral (s. IX), período en el que comienzan a documentarse por todo alAndalus, aunque en el Bajo Segura se conoce algún precedente anterior de finales del siglo VIII 55. Por el contrario, en el mediterráneo oriental ya en época tardorromana (s. V) estos vasos están bien documentados arqueológicamente, aunque su empleo se podría remontar, de forma indirecta, a la segunda centuria de nuestra era.

Gracias a la misión de Polonia en Kôm el-Dikka, antigua ciudad de Alejandría, M. Rodziewicz documentó en el denominado "sector de las cisternas" un conjunto hidráulico peculiar: un posible castellum aquae provisto de estanques de decantación (piscina limaria), hacia el que era impulsado agua mediante ingenios mecánicos movidos por animales de tiro (1984: 259-278). Conjunto que M. Rodziewicz equiparó al de Arsinoë (1984: 266), registrado en un papiro de Londres, donde un sistema hidráulico similar de principios del siglo II, elevaba agua hasta el castellum mediante un complejo de 16 ruedas con arcaduces accionadas por animales (LUCKHARD, 1914).
En este sector, que había sido remodelado a comienzos del siglo $\mathrm{V}$ tras el terremoto de 365, halló tres estancias junto al corredor oeste de la gran cisterna. Dada la proximidad al castellum M. Rodziewicz interpretó, teniendo en cuenta la labor que se realizaba en él, que dichas habitaciones estuvieron destinadas al personal especializado, establos de los animales de tiro y almacenes de útiles para la reparación y reposición de la maquinaria. En la sala meridional halló, junto a cuerdas y ganchos, un gran número de fragmentos de gadous (arcaduz) que representaba más del 60 por ciento del registro cerámico (RODZIEWICZ, 1984: 266).

Según M. Rodziewicz dichos gadous son "recipientes egipcios de función específica, para elevar el agua desde pozos y canales atados a cuerdas" (1984:267). Se trata, pues, de piezas de gran tamaño con cuerpos de tendencia apuntada con la parte superior globular o bien cilíndrico-globular, terminados en un pequeño ápice basal. El borde, ligeramente exvasado, tiene labio triangular biselado al interior o con pestaña externa. Debajo de la boca presentan una escotadura lisa poco profunda. El resto del cuerpo puede estar surcado, parcial o totalmente, por suaves ondulaciones horizontales. La base está rematada por un pequeño ápice biselado con botón central, que forma, con la parte inferior del cuerpo, un profundo entalle. Los parámetros morfométricos obtenidos del dibujo de Rodziewicz (1984: Fig. 287) ofrecen una altura de $28,4 \mathrm{~cm}$ de altura, para el único ejemplar completo, y diámetros de 13,1/14,0 cm en la boca y entre 4,2 y $5,7 \mathrm{~cm}$ en los ápices.

Los arcaduces alejandrinos servían, pues, para elevar agua en una máquina, pero desconocemos cómo era ésta, aunque la gruesa

\footnotetext{
54 En 1996 S. Gutiérrez (155) ya señalaba su ausencia en contextos arqueológicos anteriores a las postrimerías del siglo VIII. Tres lustros después, sigue sin documentarse, en esta etapa, recipientes de carácter auxiliar (cangilón/arcaduz) aplicables a las máquinas hidráulicas. Véanse también las obras de referencia La cerámica altomedieval en el sur de al-Andalus (Malpica Cuello, A. Ed., 1993) y Cerámicas tardorromanas y altomedievales en la Península Ibérica (Caballero, L., Mateos, P., Retuerce, M., Eds. 2003). En el período emiral se identifican en Valencia (Pascual, Rivera y Roselló, 2003, 113, Fig. 34), Pechina (Almería) (Acien y Martínez, 1989), Málaga (Acien et alii, 2003, 420, Fig. 6) o en Mérida (Alba y Feijoo, 2003. ,).

55 Gutiérrez Lloret, 1996, 155. En el período emiral se identifican en Valencia (Pascual, Rivera y Roselló, 2003, 113, Fig. 34), Pechina (Almería) (Acien y Martínez, 1989), Málaga (Acien et alii, 2003, 420, Fig. 6) o en Mérida (Alba y Feijoo, 2003. ,).
} 
capa de excrementos de animal hallados en la misma zona, hace pensar que se trataba de un ingenio accionado por animales de tiro.

Afortunadamente ha llegado hasta nosotros la representación de una máquina hidráulica probablemente similar a la que tratamos, que, curiosamente, también procede de Alejandría (Museo Greco-Romano de Alejandría) (Lám. 4) ${ }^{56}$. El estuco que adorna el monumento funerario de un agricultor, rememorando una escena cotidiana de su vida, nos muestra una rueda hidráulica movida por bueyes. Es una máquina compleja con una rueda vertical colocada en la boca de un pozo, unida mediante engranajes a un eje vertical con un doble travesaño al que van uncidos sendos bueyes, que marchan sobre una plataforma elevada circular, encintada con sillares.

Desde el punto de vista cronológico, los hallazgos de Kôm el-Dikka (Alejandría), como

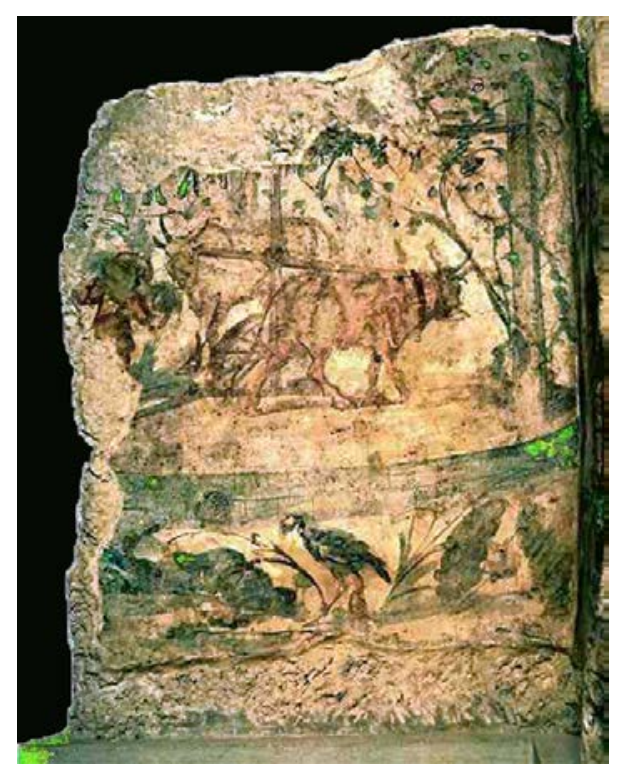

Lámina 4. Estuco representando una rueda hidráulica de tracción animal sobre plataforma elevada circular (s. I aC.-I dC.). Museo GrecoRomano de Alejandría (Egipto), sala 15. los cangilones del "sector de las cisternas" (s. V dC.) o la representación de la primera rueda hidráulica de tiro (s. I aC.-I dC.), constituyen, sin duda, los precedentes de las máquinas hidráulicas de tracción animal y de los arcaduces que reencontraremos, más tarde, en el otro extremo del mediterráneo, en Sark al-Andalus (Fig. 14). Los cangilones alejandrinos caracterizados formalmente por una escotadura debajo de la boca y un entalle profundo en el peculiar ápice que forma la base, se pueden considerar el prototipo de los arcaduces de Tudmīr que exhiben las mismas adaptaciones en ambos extremos del vaso propias del amarre próximo-distal.

Las últimas investigaciones coinciden en situar el foco de origen de las primeras ruedas elevadoras de agua el Mediterráneo oriental, posiblemente en Egipto (OJEDA CALVO, 2006: $12-13)^{57}$, y estos hallazgos confirman que su desarrollo se produjo muy probablemente en Alejandría. Si bien el estudio de la mecánica de los engranajes se remonta al siglo III aC., fue precisamente en esta ciudad donde, de la mano de Herón (de Alejandría) (s. I dC.) la mecánica y la hidráulica obtuvo nuevos avances que favorecieron, quizás, su temprana aplicación práctica como ha puesto de relieve la arqueología.

Podríamos considerar Alejandría como un centro donde conocimiento teórico y aplicación práctica cristalizan en la máquina hidráulica que conocemos como aceña o noria de tiro (o de sangre), en la que los cangilones cerámicos jugarán un papel crucial, desde el punto de vista arqueológico, al convertirse en indicadores materiales (fósil director) de una larga tradición tecnológica que se difundirá por toda la costa africana hasta el mediterráneo occidental.

56 Estuco romano encontrado en Alejandría en 1960, expuesto en la sala 15 del Museo Greco-Romano de Alejandría Alejandría (http:// www.grm.gov.eg/images/large/19.jpg). Su datación resulta muy problemática, estableciéndose un amplio margen que va del siglo I aC. a siglo I dC. (http://www.kattler.dk/schiolers/uk/antikke_oesevaerk.html)

57 Las evidencias arqueológicas (a partir del siglo II a.C.), literarias (desde el siglo III a.C.) y papirológicas (siglos III y II a.C.) señalan Egipto como la zona de origen. Papiros grecorromanos del British Museum mencionan el empleo de máquinas de agua egipcias para el regadío y diversas aplicaciones industriales (R. Ojeda Calvo 2006, 12-13) 


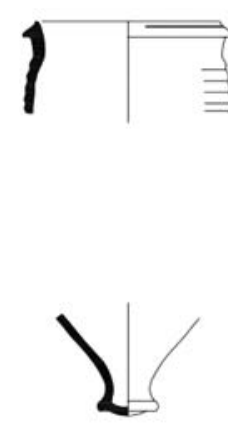

1

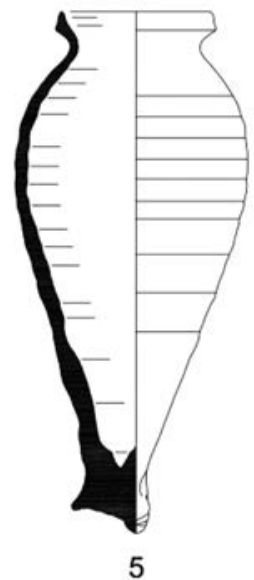

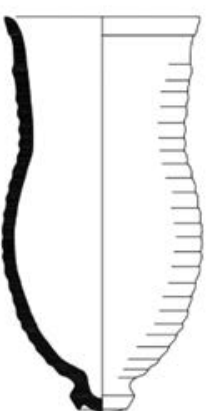

2

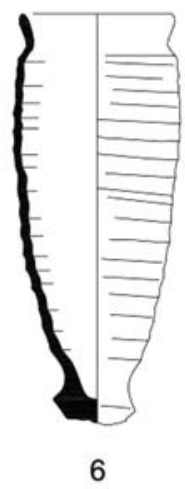

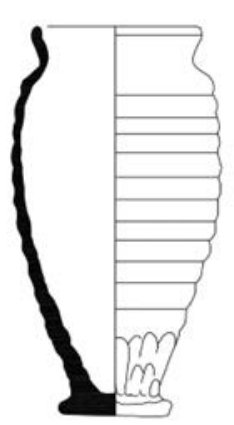

3

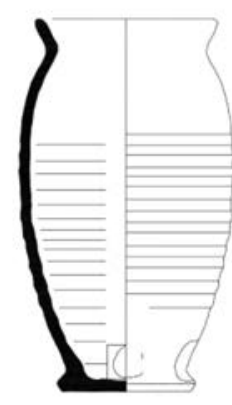

4
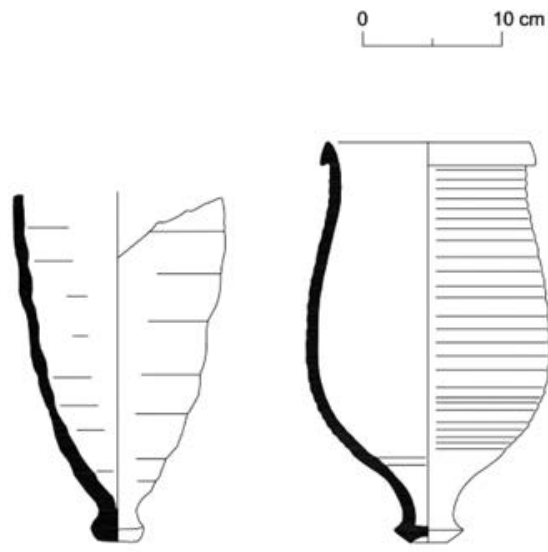

7

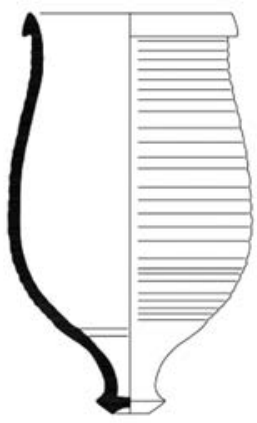

8

Figura 14. Arcaduces de amarre próximo-distal mediterráneos: 1 y 2, Kôm el-Dikka (Alejandría); 3, Rojales (Alicante); 4, Lorca (Murcia); 5, Senda de Granada (Murcia); 6, Murcia; 7, Guardamar (Alicante); 8, Palermo (Sicilia).

Concluiremos diciendo que la mecánica hidráulica aplicada a la aceña procede del Mediterráneo oriental, pero que fue la cultura árabe quien, tras su perfeccionamiento, la difundió en al-Andalus, si bien, mundo romano y musulmán tuvieron una misma fuente tecnológica de origen: los ingenieros helenísticos del siglo III aC. y sus herederos de la escuela de Alejandría (s. I dC.).

\subsection{Los arcaduces de amarre próximo- distal de Senda de Granada, evolución tipológica y encuadre cronológico}

Los arcaduces de Senda de Granada pertenecen al grupo tipológico que, en al-Andalus, aparece casi exclusivamente ${ }^{58}$ en la Cora de Tudmìr a lo largo de la vega del río Segura, en sus tramos bajo, medio y alto (Lám. 5). Se trata de recipientes de tendencia troncocónica invertida con una marcada inflexión redondeada en el hombro y borde exvasado, ligeramente engrosado. La base suele mostrar diversas soluciones que van desde la forma plana o ligeramente convexa, al ápice macizo cilíndrico, cónico o el irregular esférico.

En el bajo Segura los encontramos en Cabezo del Molino (Rojales), La Rábita (Guardamar del Segura), Castillo de la Sierra (Callosa de Segura) y en Cabecicos Verdes (Orihuela), yacimientos todos ellos de la provincia de Alicante (Fig. 13). En la vega media y alta se hallan el casco urbano de Murcia (Madinat Mursiya), en Senda de Granada y Siyâsa (Cieza). Los ejemplares más antiguos, fechados entre media-

58 En Almadén y Mallorca se localizan sendos arcaduces parecidos de cronología incierta (ROSELLÓ BORDOY, 1978, 34) y en Valencia un ápice esférico hueco (PASCUAL et alii, 2003). 


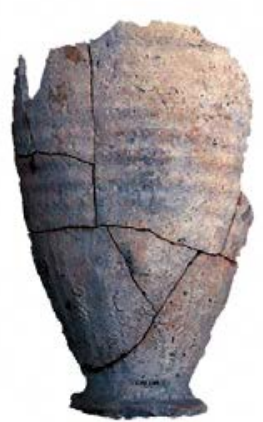

1

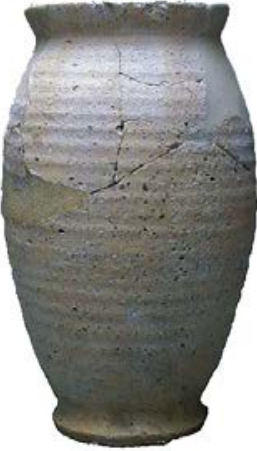

2

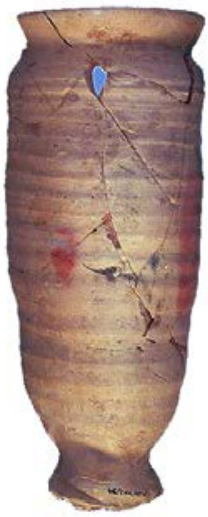

3

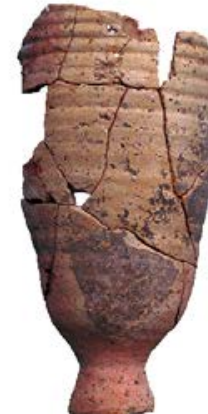

4

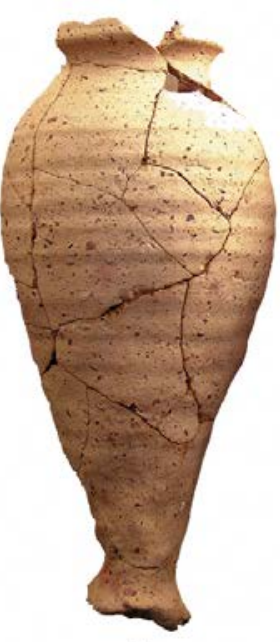

5

Lámina 5. Arcaduces de Tudmir: 1, Cabezo del Molino, Rojales (Alicante) (Foto: S. Gutiérrez); 2, Glorieta de San Vicente, Lorca (Murcia) (Foto: Museo Arqueológico de Lorca); 3, Alfar calle Cortés (Murcia); 4 y 5, Senda de Granada, Espinardo (Murcia).

dos del siglo VIII y primera mitad del siglo IX (GUTIÉRREZ LLORET, 1993: 55; 1996 a y b), proceden del Cabezo del Molino (Rojales, Alicante). En Castillo de la Sierra y Cabecicos Verdes datan del tránsito del S. IX al S. X (GUTIÉRREZ LLORET, 1996a: 367 y 353). De época califal avanzada son los ejemplares de la Rábita de Guardamar (Alicante) y los del alfar antiguo de San Nicolás de Murcia (GUTIÉRREZ LLORET, 1993: 56). Y de la segunda mitad del siglo X o principios del XI, los del alfar de la Calle Cortés de Murcia (MUÑOZ LÓPEZ, 1992: 182).

En Madinat Mursiya, exceptuando los dos alfares (antiguo de San Nicolás y calle Cortés) y Senda de Granada, no se han documentado otros arcaduces de amarre próximo-distal. En el resto de la región de Murcia sólo se tiene constancia de otro par de ejemplares: el ya citado de Madinat Siyâsa, hallado en un vertedero (NAVARRO y JIMÉNEZ, 2003: 112, fig. 3.5) ${ }^{59}$, y otro en la Glorieta de San Vicente de Lorca, de localización parecida ${ }^{60}$.

Dentro del grupo de amarre próximo-distal se aprecian diferencias morfológicas en el pie que podrían tener trascendencia cronológica. En época emiral (finales del s. VIII y siglo IX) los arcaduces terminan en una peana discoidal plana o ligeramente convexa (Cabezo del Molino y de Glorieta de San Vicente). Hacia finales del siglo IX o principios del X, se atestiguan los primeros ápices sólidos con reborde bajo formando una pequeña peana (Castillo de la Sierra). Y a partir del siglo X (período califal) los arcaduces ya sólo muestran conteras sólidas con diversos acabados (La Rábitat, Senda de Granada y alfar de la calle Cortés) ${ }^{61}$ (Fig. 15).

59 Además de recipiente publicado, don J. Salmerón (Dr. del Museo Arqueológico Municipal de Cieza) ha informado del hallazgo de otros ejemplares similares localizados en la letrina de algunas casas de Siyâsa.

60 En el silo-vertedero se documentó un conjunto de materiales cerámicos de la segunda mitad del siglo IX y primera mitad del X, entre los que se documentaron marmitas (GUTIÉRREZ 1996, tipo M4.1.2), jarrito/as decorados con bandas paralelas de manganeso, tinajas (GUTIÉRREZ 1996, tipos M10.2 y M10.3), tapaderas planas, una base de candil de piquera (ROSSELLÓ 1978, tipo IV) y un fondo vidriado verdoso por fuera y amarillento en el interior.

61 Tanto el ápice como las peanas planas de estos recipientes no tenían función sustentante aunque, en algunos casos, la podía ejercer. La observación de esta parte permite reconocer que esta porción no es más que un trozo de la pella de barro sobre la que se modelaba la pieza en el torno. Cuando terminaba esta operación se cortaba para desprenderla del torno. La base del recipiente era objeto un acabado manual somero que, en muchos casos, deja ver esta forma de proceder. En el caso de los ejemplares del Cabezo del Molino (Rojales, Alicante) se ve las huellas helicoidales dejadas por el hilo de corte (Gutiérrez Lloret 1996, 9); en alfar de la calle Cortés de Murcia), la pella se ve tal cual salió del torno; y en los ápices de Senda de Granada, las terminaciones esféricas con digitaciones no son más que el pegote de barro terminal torsionado sobre sí mismo. 


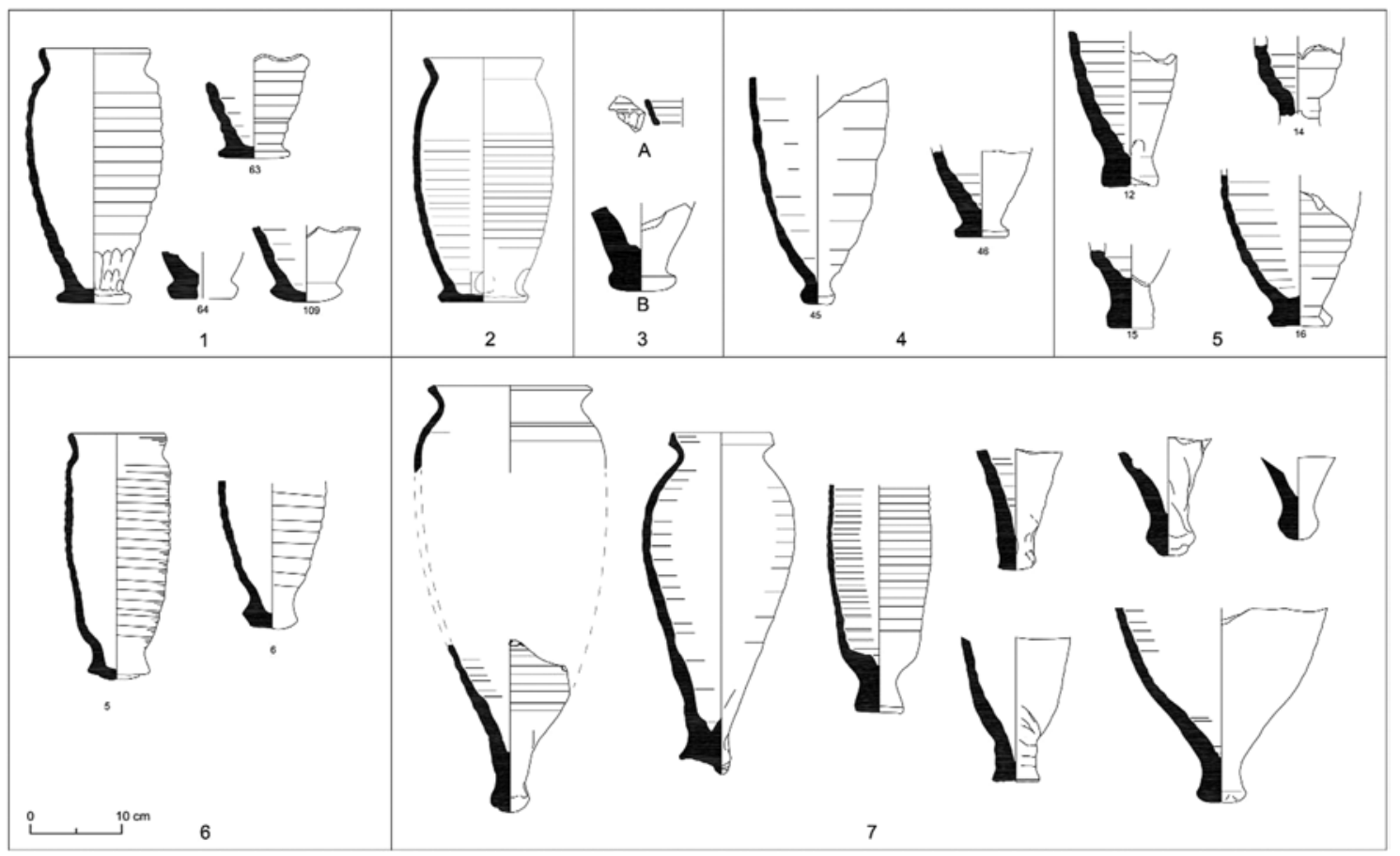

Figura 15. 1: Cabezo del Molino (Rojales, Alicante). 2: Glorieta de San Vicente (Lorca, Murcia). 3: A, Cabecicos Verdes (Orihuela, Alicante); B, Castillo de la Sierra (Callosa del Segura/Cox, Alicante). 4: La Rábita (Guardamar del Segura, Alicante). 5: Alfar antiguo de San Nicolás (Murcia). 6: Alfar calle Cortés (Murcia). 7: Senda de Granada (Espinardo, Murcia) ${ }^{65}$.

En Senda de Granada los arcaduces emirales con pie plano están ausentes, registrándose sólo los ápices macizos en sus diversas variantes (cilíndricos, cónicos o esféricos). De todos los ejemplares tudmiríes citados, los modelos más cercanos con bases de tendencia cilíndrica y cónica, con o sin bisel inferior, a excepción de los esféricos irregulares, proceden del alfar antiguo de San Nicolás (Madinat Mursiya), al que se atribuye una datación de la segunda mitad del siglo X (GUTIÉRREZ LLORET, 1992: 281, figs. Y36), y de la calle Cortés ${ }^{62}$, fecha- dos en el siglo X-XI (MUÑOZ LÓPEZ, 1992: 182). LOS ápices de tendencia esférica sólo se hallan en Senda de Granada, sin otros paralelos conocidos, si exceptuamos aquellos de reducido tamaño con forma de botón biselado que presenta algún ejemplar de La Rábita (Guardamar, Alicante) (AZUAR RUIZ et alii, 1989) o del alfar de la calle Cortés de Murcia ${ }^{63}$, de cronología semejante (segunda mitad del siglo X) ${ }^{64}$.

En cualquier caso, dado que los ápices macizos se atestiguan en Tudmîr desde fina-

62 En el interior de un horno se documentó un grupo de arcaduces de amarre próximo-distal y ápice macizo cuya semejanza es manifiesta, tanto en la formación del pie con un "pegote" de arcilla, como en la burda terminación con un giro para formar el "gollete". El alfar es datado entre el s. X y un momento inicial del s. XI (MUÑOZ LÓPEZ, 1992, 182).

63 Pieza depositada en el Museo Arqueológico de Murcia (no dibujada y no publicada). Éstos se diferencian en el rebaje basal que se les practica para disminuir su espesor, paso del acabado final que se obvia en los de Senda de Granada, lo que les confiere e aspecto tosco y esférico que los caracteriza.

64 La observación directa de los ejemplares del alfar de la calle Cortés de Murcia, permite comprobar en la misma hornada la coexistencia de ápices macizos recortados por debajo en bisel con otros ejemplares de botón recortado de tamaño y forma idéntica a de La Rábita T32.2 (GUTIÉRREZ LLORET, 1996, 122). Entre los arcaduces de Senda de Granada tipos I-A y I-B no podemos verificar el supuesto proceso evolutivo de reducción del tamaño de los ápices (GUTIÉRREZ LLORET, 1996, 153). Sólo advertimos el tamaño uniforme de los mismos que oscila entre 4 y $6 \mathrm{~cm}$ de grosor y la aparición del engrosamiento esférico irregular.

65 Cabezo del Molino n. 1, 2, 3 (GUTIÉRREZ LLORET, 1992, 162, figs. Y20); Cabecicos Verdes, n. 4 (GUTIÉRREZ LLORET, 1992, 154, figs. Y18); Castillo de la Sierra/Cox, n. 6 (GUTIÉRREZ LLORET, 1992, 146, figs. Y16); La Rábita, n. 7 (GUTIÉRREZ LLORET, 1992, 180, figs. Y25); Alfar antiguo de San Nicolás n. 8 (GUTIÉRREZ LLORET, 1992, 281, figs. Y36); Alfar calle Cortés n. 9 (MUÑOZ LÓPEZ, 1992, fig. 3). Glorieta de San Vicente n. 5 y Senda de Granada n. 10: ArqueoTec. 
les del período emiral (Castillo de la Sierra de Callosa, en Alicante), no descartamos que en Senda de Granada comenzaran a emplearse también en la primera mitad del siglo X, momento en el que se construirían las aceñas más antiguas ( 1 y 3). En este sentido hemos de considerar, además, que los ejemplares de Senda de Granada muestran ciertas variaciones morfo-métricas, que parecen indicar la existencia de un proceso evolutivo dentro de este grupo, antes de producirse el cese productivo de este modelo, en pro del cambio tecnológico definitivo hacia la centralización del punto de amarre inferior; proceso de renovación que estimamos se produjo en Murcia hacia el siglo XII.

En la aceña 2, en consonancia con las dimensiones de la nueva noria, los arcaduces aumentan de tamaño y sufren algunos cambios (tipo I-B). La embocadura de los recipientes se ensancha y se hace más alta, el cuello se entalla aún más para proporcionar una zona de amarre más segura y el cuerpo se agranda y gana altura, en tanto que el borde y el ápice adquieren mayor variedad de tipos ${ }^{66}$. La presencia de un fragmento de galbo indeterminado de verde y morado en el depósito de amortización en esta aceña, nos proporciona un elemento de datación interesante que permite determinar su fecha de abandono, terminus post quem entre la segunda mitad del siglo X o principios del siglo XI, momento en el que se constata esta producción califal en la cercana Madinat Mursiya (alfar Antiguo de San Nicolás de Murcia) (NAVARRO PALAZÓN, 1990). En sentido contrario, la ausencia absoluta de arcaduces de engarce próximo-medial (tipo II) en el relleno del pozo, nos remite a un momento indeterminado previo al cambio de modelo que, en la Murcia andalusí (calle del Pilar), se atestigua hacia el XII (NAVARRO PALAZÓN, 1986: 259).
Para fechar este momento de tránsito, con las debidas cautelas, hemos recurrido también al análisis de las estructuras arquitectónicas de las aceñas y en concreto a sus respectivos tipos de fábrica. El reciente estudio sobre las técnicas constructivas de la Murcia andalusí elaborado por J. Navarro y P. Jiménez, nos permite identificarlas grosso modo con las fábricas denominadas "antigua" (aceña 1 y 3) y "reciente" (aceñas 2, 3 y 4), fechadas en los siglos X-XI y XII-XIII (NAVARRO y JIMÉNEZ, 2011) respectivamente, si bien es necesario señalar que el análisis dichos autores se restringe al estudio de los aparejos en el ámbito urbano y no contempla las obras hidráulicas de carácter rural. No obstante, en el caso de la fábrica "antigua" podríamos considerar que la relativa semejanza del aparejo no es sólo de carácter formal sino también estructural, pues el pozo mismo de la aceña se podría equiparar al tramo de cimiento o zócalo que se halla hundido en el subsuelo en el medio urbano ${ }^{67}$. Por otra parte, en el medio rural también podemos atribuir al encofrado de hormigón una cronología relativa posterior a la obra de spicatum. Si bien en el proceso de remplazo de la aceña 2 por la 1 , no disponemos de indicios estratigráficos en los que apoyarnos, en la aceña 3 (de encofrado de hormigón), por el contrario, si disponemos de tal registro pues conserva un trozo de la fábrica "antigua" (que componía el pozo originario) recibiendo el paramento encofrado de cal, hecho que nos permite confirmar la datación relativa más reciente del encofrado en el proceso de remplazo de una técnica por otra, también en las obras hidráulicas rurales.

En la sucesión de las aceñas 1 y 2 constatamos la sustitución de la primera, de fábrica de mampostería en espiga, por la segunda de mayor tamaño construida con encofrado de cal. Consideramos, pues, que la aceña 1

66 Tal diversidad podría estar motivada, primero, por el prolongado uso de la aceña y luego por propio carácter de los arcaduces, un producto artesanal muy frágil, necesariamente renovable y de escaso valor, cuya elaboración pretendía resultados meramente prácticos, es decir, los adecuados puntos de amarre (cuello acentuado y extremo basal reforzado) más que una producción cuidada, más propia de la vajilla doméstica, de mesa o almacenaje

67 La obra que equiparamos con la fábrica "antigua" presenta los mampuestos colocados en espiga si bien se diferencia de ésta en la ausencia de tongadas intermedias de mortero. No obstante, la ausencia de este material ha de ponerse más bien en relación con una técnica constructiva propia de los pozos, que con la cualidad de una técnica diferente a la empleada en el medio urbano. 
tras un periodo indeterminado funcionando (probablemente desde su construcción en la primera mitad del siglo X), fue amortizada ya en el siglo XI y remplazada por la número 2, un ingenio nuevo de mayor capacidad extractiva, si consideramos el calibre de la cañería de su toma en la acequia, el tamaño del pozo y, por ende, el diámetro de la noria que albergaría 68 .

Así, en razón de la fábrica de construcción de la aceña 1, de la decoración incisa ondulada a peine de sus atanores (característica de
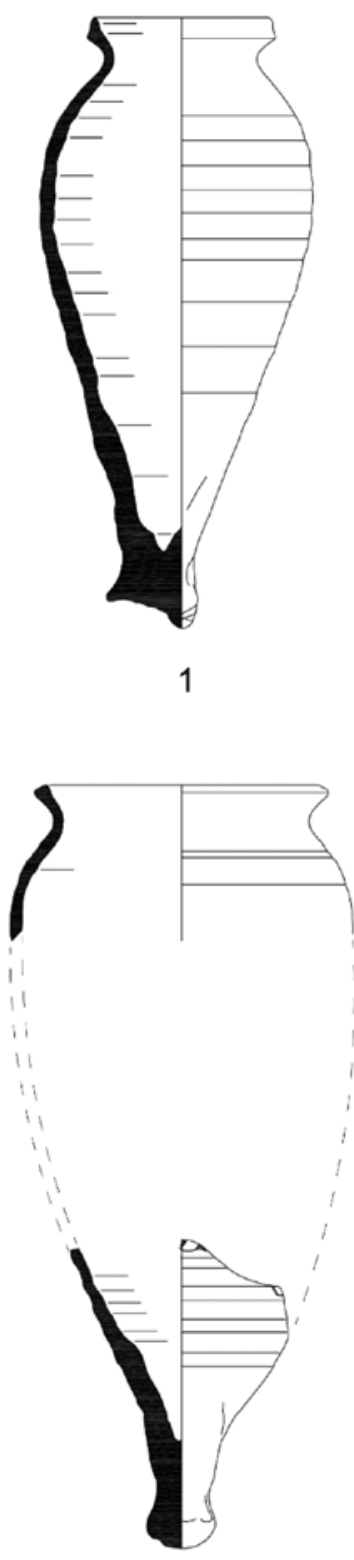

3
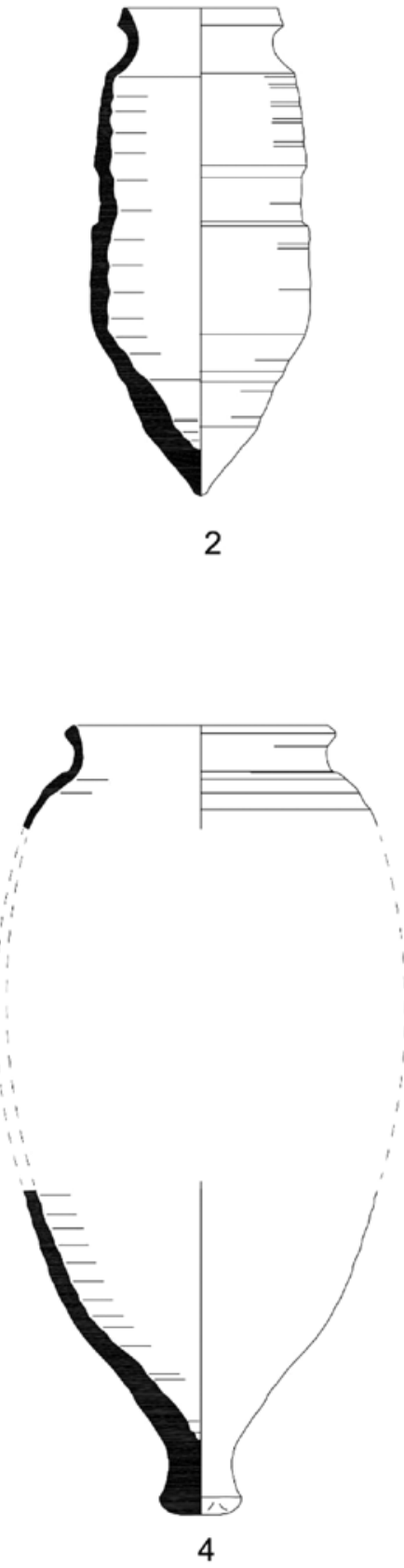

Figura 16. Arcaduces de Senda de Granada (Espinardo, Murcia): 1, arcaduz tipo I-A; 3-4 arcaduz tipo I-B; 2, arcaduz tipo II.

68 No sabemos si este proceso tuvo que ver con alguna remodelación del azud de la Contraparada que, quizás al proporcionar mayor caudal a las acequias, favoreció la construcción de un ingenio de mayor capacidad de extracción de agua. 
la vajilla del siglo $X{ }^{69}$ ) y de este proceso local de renovación, inferimos que los arcaduces más antiguos son del tipo I-A (Fig. 16, 1), de cuerpo troncocónico, hombro globulary ápice cilíndrico irregular macizo ${ }^{70}$.

En el siglo siguiente (s. XI) estos arcaduces fueron remplazados en la aceña 2 por los del tipo I-B (Fig. 16, 3-4), manteniéndose en uso, al menos, dada la ausencia de arcaduces con escotadura central y base puntiaguda (tipo II) (Fig. 16, 2), hasta finales la centuria o comienzos de la siguiente (s. XII), fecha que se acepta para el momento de implantación plena del arcaduz de fijación próximo-medial y, por tanto, del abandono del anterior en Murcia.

\section{SENDA DE GRANADA Y LA CREACIÓN DEL SISTEMA DE IRRIGACIÓN MURCIANO ${ }^{71}$}

A lo largo de este trabajo hemos tenido oportunidad de comprobar el origen andalusí del sistema de riego documentado en Senda de Granada. La secuencia estratigráfica registrada en sus tres cauces permite descartar un origen preárabe ${ }^{72} y$, por el contrario, afirmar su construcción en época medieval islámica. A su vez, la datación relativa que ofrece la secuencia estratigráfica se ha visto confirmada por la indudable filiación islámica de las estructuras hidráulicas y los recipientes cerámicos asociados que acabamos de estudiar.

Históricamente el comienzo de la configuración del sistema hidráulico andalusí murciano cabría situarlo, tras la fundación de Madinat Mursiya ordenada por 'A Abd Al-Rahmān II (822852) en el año 825, entre finales de esta centuria y el período de estabilidad política y militar sucedido en el siglo siguiente (s. X) -durante los reinados de cAbd Al-Rahmān III (929-961) o Al-Hakam II (961-976) 73 - . Si bien algún autor desestima, incluso, que este tuviera lugar en una fecha anterior al S. XI (ROBLES, 2006, 9), fecha en la que el geógrafo árabe Al-cUdrī (s. XI) menciona por primera vez la existencia de una acequia de riego en Murcia (MOLINA LÓPEZ, 1972).

Respecto de su formación se acepta de forma generalizada un proceso de creación progresivo según el cual las respectivas acequias madre (Aljufía y Alquibla) son los cauces primigenios a partir de los cuales se desarrolló el resto del sistema, siendo éstos, por tanto, los canales de mayor antigüedad. Según esto el heredamiento norte alcanza su máxima extensión cuando se abre Churra la Vieja en la etapa final de construcción, en un momento avanzado del período andalusí (ss. XII-XIII), dado que su trazado discurre por la cota más alta del heredamiento, solo superada ya en

69 La decoración incisa con motivos peinados ondulados se considera un rasgo decorativo propio de los talleres del sureste peninsular, desde finales del siglo IX a fines del X (GUTIÉRREZ LLORET 1996, 156).

70 Es cierto que los materiales hallados en el interior de la aceña 1, pueden haber sido depositados, no en el momento mismo de su abandono, sino en una etapa posterior, quizás durante el funcionamiento de la n. 2. Sin embargo, las diferencias morfo-métricas constatadas entre los arcaduces de uno y otro pozo, indican que el relleno se produjo en momentos diferentes. En la aceña 1 están ausentes los arcaduces de mayor tamaño (tipo I-B) documentados en la 2. Además hemos de tener en cuenta que el pozo abierto de la aceña 1 entrañaría riesgos para el tránsito de los animales de tiro y permitiría el paso de agua desde la acequia.

71 Sobre la historia y la creación de la huerta de Murcia, véase "Histoire d'eau: la huerta de Murcie” cap. 12 de La Noria et l'aubergine et le fellah. Archéologie des espaces irrigués dans l'occident musulman médiéval (BAZZANA y DE MEULEMEESTER, 2009: 353-394)

72 Algunos autores apuntan un posible origen romano aduciendo cierta geometría del parcelario de la huerta de Murcia (ROSSELLÓ y CANO, 1974) o la existencia de estructuras hidráulicas antiguas, tipo qanat, a las que se atribuye un origen pre-árabe; no obstante, esta opinión está aún por demostrar y los resultados estratigráficos de Senda de Granada lo contradicen. En el área que estudiamos la acequia Alfatego discurre sobre los niveles tardoantiguos previamente amortizados por un manto de sedimentos arcillosos. El quijero meridional de Churra la Vieja se superpone al nivel de sepulturas de la Necrópolis Norte (sector C1 de la excavación) y en la acequia del Tablacho (antiguo tramo de Alfatego) ocurre otro tanto, cuando su cauce cruza sobre una instalación productiva romana. En el heredamiento de mediodía conocemos un caso parecido localizado bajo el espacio que ocupan las nuevas instalaciones del Museo Etnológico de la Huerta de Murcia, entre la acequia mayor de Barreras (Alquibla) y la Turbedal, donde en el curso de su edificación se hallaron diversas construcciones romanas por debajo del nivel de ambas acequias. En este mismo sentido, como señalan A. Bazzana y J. De Meulemeester (2009: 363), la hipótesis sobre el supuesto origen romano del Azud de la Contraparada carece de datos convincentes.

73 A. Bazzana y J. De Meulemeester, estiman que este momento transcurre en el tercer período, es decir, entre los siglos X y XI, cuando el Estado acomete de un modo racional la organización hidráulica de la zona más baja del valle, que requirió, a su vez, importantes obras complementarias de drenaje (2009: 359-360). 
época cristiana con la creación de una nueva acequia mayor: Churra la Nueva.

Sin embargo, el registro arqueológico obtenido en Senda de Granada invita a replantear la datación del proceso evolutivo considerado hasta ahora, dado que la cronología que aportan tanto los arcaduces de fijación próximo-distal, como la fábrica de los pozos de las aceñas asociadas a Churra la Vieja es, por el contrario, temprana: el siglo $X$.

Hasta ahora la ausencia de datos arqueológicos referidos a este hecho fundacional, hacía que el análisis de las fuentes árabes y cristianas o la interpretación histórica reciente fuera el único recurso disponible para dilucidar cuándo y cómo se puso en marcha el regadío en Murcia. Afortunadamente ahora disponemos de la datación arqueológica que carecíamos, estableciendo hitos cronológicos que acotan temporalmente los hechos históricos referidos por las fuentes.

No ha sido hasta ahora cuando se ha dispuesto del suficiente registro arqueológico material para comprender el proceso de formación de este sector del heredamiento norte, verificar su extensión y datarlo en el siglo $\mathrm{X}$, hecho de gran relevancia que, de forma indirecta, permite determinar terminus ante quem la creación del sistema hidráulico. Así, pues, si las acequias Churra la Vieja y Alfatego se encontraban plenamente operativas en esta fecha (con sus respectivos ingenios hidráulicos), se ha de aceptar que la acequia mayor de Aljufía, incluido, probablemente, el azud Mayor de la Contraparada, hubieron de ser construidos, indiscutiblemente, en un momento anterior: muy probablemente, a finales del siglo IX o comienzos del $X$.

\section{FUENTES}

AL-cUDRĪ, Al-masālik ilā gamīc al-mamālik; Al Ahwani (ed.), Fragmentos geográfico históricos de Al-masālik ilā gamīc al-mamālik, Madrid, 1965; E. Molina López (trad.), La Cora de Tudmìr según al-cudrī (s. xi). Aportaciones al estudio geográfico descriptivo del SE peninsular, «Cuadernos de Historia del Islam», 4; serie monográfica, no 3, 1972.
IBN AL-AWWAM, Libro de agricultura (ed. Y trad. J.A. Banqueri; estudio preliminar y notas de J.E. Hernández y E. García), 2 vols., Madrid, 1988 (ed. Facsímil de 1802).

ISIDORO DE SEVILLA, Etimologías (Etymologiae - Originum sive etymologiarum libri viginti), OROZ RETA, J., MARCOS CASQUERO, M. A. (eds.), ed. bilingüe, Madrid, 1982 B.A.C.

VITRUVIO POLIÓN, MARCO, Los diez libros de Arquitectura (De Architectura). Editorial Alianza. Madrid, 2009

\section{BIBLIOGRAFÍA}

ACIÉN ALMANSA, M., MARTíNEZ MADRID, R., (1989): "Cerámica islámica arcaica del sureste de al-Andalus", Boletín de Arqueología Medieval. Madrid, 3.

ACIÉN ALMANSA, M., CASTAÑO, J.M., NAVARRO, I., SALADO, J.B., VERA, M. (2003): "Cerámicas tardorromanas y altomedievales en Málaga, Ronda y Morón”, en CABALLERO, L., MATEOS, P., RETUERCE, M. (Ed.), Cerámicas tardorromanas y altomedievales en la Península Ibérica. Anejos de Archivo Español de Arqueología XXVIII. P. 411-454

AL-HASSAN, R., HILL, D.R. (1986): Islamic Technology: An Illustrated History, Cambridge, UNESCO y Cambridge University Press.

ALBA CALZADO, M., FEIJOO, S. (2003): "Pautas evolutivas de la cerámica común de Mérida en épocas visigoda y emiral" en CABALLERO, L., MATEOS, P., RETUERCE, M. (Ed.), Cerámicas tardorromanas y altomedievales en la Península Ibérica. Anejos de Archivo Español de Arqueología XXVIII. P. 483-504

ALBA CALZADO, M., GUTIÉRREZ LLORET, S. (2008): "Las producciones de transición al Mundo Islámico: el problema de la cerámica paleoandalusí (siglos VIII-IX)" en BERNAL CASASOLA, D., RIBERA LACOMBA, A. (Ed.), Cerámicas hispanorromanas. Un estado de la cuestión.

AMORÓS, V., CAÑAVATE, V., GUTIERREZ, S. y SARABIA, J, (2012): "Cerámica altomedieval en el Tolmo de Minateda (Hellín, Albacete, España)". En: Atti del IX Congresso Internazionale sulla Ceramica Medievale nel Mediterraneo (Venezia, 2009), pp. 246-257.

ARCIFA, L., LESNES, E. (1996): "Ceramica in uso a Palermo da X al XV secolo". In VI Congrès Interntional sur la Céramique Médiévale en Méditerranée, Aix-en-Provence, 1995

ARCIFA, L., LESNES, E. (1997): Primi dati sulle produzioni ceramiche palermitane dal X al XV secolo, ibid., p. 412.

ARCIFA, L. (2010): "Indicatori archeologici per l'alto Medioevo nella Sicilia orientale". In: PENSABENE, P. (a cura di), Piazza Armerina Villa del Casale e la Sicilia tra tardoantico e Medioevo.

AZUAR RUIZ, R. (coord.) (1989): La rábita califal de las dunas de Guardamar (Alicante). Cerámica. Epigrafía. Fauna. Malacología. Memorias del Museo Arqueológico Provincial. Diputación Provincial de Alicante. 
BARCELÓ PERELLÓ, M. (1989): "El diseño de espacios irrigados al-Andalus: un enunciado de principios generales", El agua en zonas áridas: Arqueología e Historia: I Coloquio de Historia y Medio Físico, Instituto de Estudios Almerienses. Departamento de Historia, Vol. I, p. XV-XLIX

BARCELÓ PERELLÓ, M. (1996): El agua que no duerme. Granada.

BALLESTEROS ARIAS, P.; EIROA, J.; KIRCHNER, H.; FERNÁNDEZ MIER, M.; ORTEGA ORTEGA, J.; QUIRÓS CASTILLO, J.A.; RETAMERO, F.; SITJES, E.; TORRÓ, J.; VIGIL-ESCALERA GUIRADO, A. (2010): "Por una arqueología agraria de las sociedades medievales hispánicas. Propuesta de un protocolo de investigación." En HELENA KIRCHNER (Ed.) Por una arqueología agraria. Perspectivas de investigación sobre espacios de cultivo en las sociedades medievales hispánicas. BAR International Series 2062, 2010

BAZZANA, A. (1983): La cerámica islámica en la ciudad de Valencia. Valencia.

BAZZANA, A. (1987): "Una noria árabe en la huerta de Oliva (Valencia)" II Congreso de Arqueología Medieval Española. Tomo II. Madrid. Pp. 421-432.

BAZZANA, A., CLIMENT, S., MONTMESSIN, Y., (1987): El yacimiento medieval de "Les Jovades", Oliva (Valencia). Ayuntamiento de Oliva, Oliva.

BAZZANA, A.; MONTMESSIN, Y. (2006): Na'ura et saniya dans l'hydraulique agricole d'al-Andalus à la lumière des fouilles de "Les Jovades" (Oliva, Valence). En: CRESSIER, P. (ed.) La Maîtrise de l'eau en al-Andalus. Paysages, pratiques et techniques. Madrid, Casa de Velázquez, pp. 209-287.

BAZZANA, A. (2009): "Techniques hydrauliques et gestion des espaces irrigués dans les huertas de murciennes (ixe-xiiie siècles). Le mode rural dans l'Occident musulman médiéval". Revue des Mondes Musulmans et de la Méditerranée, 126, P. 27-46. Puesta en línea el 05 de junio de 2012. URL: http://remmm.revues.org/6444

BAZZANA, A., BEDIA, J. (2009): "Saltés. Un asentamiento islámico en las Marismas del Odiel, Huelva”. Huelva arqueológica, 21 (Casa de Velázquez - Diputación Provincial de Huelva), pp. 207 y 237.

BAZZANA, A., DE MEULEMEESTER, J. (2009): "La noria, l'aubergine et le fellah. Archéologie des espaces irrigués dans l'Occiddent musulman médiéval (9e-15e siècles)", Archaeological Reports Ghent Unviversity, 6, Gent (Bélgica), $498 \mathrm{p}$.

BELANDO Y MELENDEZ, J. (1878): Estudio sobre el río Segura y la huerta de Murcia. El Album, Murcia

BENABAT HIERRO, Y., PÉREZ MACÍAS, J.A. (2009): "La Ollita, una noria islámica en Niebla" Huelva en su Historia, 2a época, p. 233-243.

BERTRAND, M., CRESSIER, P. (1985): "Irrigation et aménagement du territoir dans le vallée de l'Andarax (Almería): les réseaux anciens de Ragol", Mélanges de la Casa Velázquez, XXI, p. 115-135.

BOSCH FERRO, C., CHINCHILLA GÓMEZ, M. (1987): "Formas cerámicas auxiliares: anafes, arcaduces y otras", Congreso de Arqueología Medieval Española. Tomo II. Madrid. P.491-500.
CABALLERO, L., MATEOS, P., RETUERCE, M. (Eds.) (2003): Cerámicas tardorromanas y altomedievales en la Península Ibérica. Anejos de Archivo Español de Arqueología XXVIII

CARMONA GONZÁLEZ, A. (1989) "Murcia ¿Una fundación árabe? (Nuevos datos y conclusiones)" Murcia Musulmana, p. $85-147$

CARMONA, A., POCKLINTONG, R. (2008): Agua e irrigación de la Murcia árabe. Murcia.

CARO BAROJA, J. (1954). "Norias, Azudas y Aceñas" en Tecnología Popular Española. Artes del Tiempo y del Espacio. P. 239-407.

CASTILLO ARMENTEROS, J. C. (1997): "Las primeras fases de ocupación islámica de Marroquíes Bajos (Jaén)", Arqueología y Territorio Medieval, 4, pp. 39-58.

CAVILLA SÁNCHEZ-MOLERO, F. (2005): Cerámica Almohade de la Isla de Cádiz (Yazirat Qadis). Universidad de Cádiz

CRESSIER, P. (1989): "Archeologie des estructures hydrauliques en Al-Andalus”, El agua en zonas áridas: Arqueología e Historia: I Coloquio de Historia y Medio Físico. Instituto de Estudios Almerienses. Departamento de Historia, p. LIII-LXXXVIII.

COLIN, G.S. (1932): "La noria marocaine et les machines hydrauliques dans le monde árabe” Hespéris, XIV, p. 22-60

DÍAZ CASSOU, P., (1879): Memoria sobre los riegos del Segura que, por encargo de la Comisión Representativa de Hacendados de la Huerta de Murcia. Murcia.

DÍAZ CASSOU, P., (1889): Ordenanzas y costumbres de la Huerta de Murcia / compiladas y comentadas por Pedro Díaz Cassou; con un estudio preliminar del Sr. D. Francisco Silvela de Levielleuze. Madrid.

DUDA, D., (1970): Spanisch-islamische keramik aus Almería, Vom 12

EIROA RODRÍGUEZ, J.A. (2010): "Arqueología de los espacios agrarios andalusíes en el sureste peninsular: nuevas perspectivas desde la periferia" En HELENA KIRCHNER (Ed.) Por una arqueología agraria. Perspectivas de investigación sobre espacios de cultivo en las sociedades medievales hispánicas. BAR International Series 2062, 2010

FUERTES SANTOS, M.C. (2010): La cerámica medieval de Cercadilla, Córdoba. Tipología, decoración y función. JUNTA DE ANDALUCÍA. Consejería de Cultura.

GARCÍA BLÁNQUEZ, L. A.; CERDÁ MONDÉJAR, C. (2007): "Estructuras hidráulicas medievales: tres aceñas y un tablacho en las acequias Churra la Vieja y Alfatego. Senda de Granada (Murcia)". Revista Murciana de Antropología, 14, pp. 343-362.

GARCÍA BLÁNQUEZ, L. A., (2010): "Senda de Granada: un asentamiento rural tardoantiguo en el entorno de Murcia” en NOGUERA CELDRÁN, J.M. (Ed.) Poblamiento rural romano en el sureste de Hispania.15 años después. Murcia 2010. P. 467-513. 
GARCÍA BLÁNQUEZ, L. A. (E.P.): "El sistema hidráulico andalusí de Senda de Granada: las aceñas de acequia, una estructura hidráulica singular. Antecedentes tecnológicos y propuesta funcional”.

GLICK, T.F. (1970): Irrigation and Society in Medieval Valencia. Massachusetts.

GLICK, T.F. (1988): Regadío y sociedad en la Valencia medieval. Valencia.

GLICK, T.F. (1992): "Regadío y técnicas agrícolas en AlAndalus. Su difusión según un eje Este-Oeste", en Actas del I Seminario sobre la Caña de Azúcar. La Caña de Azúcar en tiempos de los Grandes Descubrimientos (1450-1550), Granada, 1990, pp. 83-98.

GLICK, T.F. (1992): Tecnología, ciencia y cultura en la España medieval, Madrid, Alianza Universidad.

GLICK, T.F. (1999): Islamic and Christian Spain in the early middle ages. Comparative Perspectives on Social and Cultural Formation. (Edición impresa: Princenton University Press, 1979)

GLICK, T.F. (2001): The Irrigation Communities of Medieval Valencia

GUTIÉRREZ LLORET, S. (1986): "Cerámicas comunes altomedievales: contribución al estudio del tránsito de la antigüedad al mundo paleoislámico en las comarcas meridionales del País Valenciano". Lvcentvm, 5

GUTIÉRREZ LLORET, S. (1988): Cerámica común paleoandalusí del sur de Alicante (siglos VII-X). Alicante.

GUTIÉRREZ LLORET, S. (1992): El tránsito de la Antigüedad tardía al mundo islámico en la Cora de Tudmir: cultura material y poblamiento paloandalusí. Tesis Doctoral Universidad de Alicante 1992.

GUTIÉRREZ LLORET, S. (1993): "La cerámica paleoandalusí del sureste peninsular (Tudmīr): producción y distribución" en MALPICA CUELLO, A. (Ed.) La cerámica Altomedieval en el sur de al-Andalus. Granada, p. 38-65.

GUTIÉRREZ LLORET, S. (1996-a): La Cora de Tudmir: de la antigüedad tardía al mundo islámico. Poblamiento y cultura material. Casa de Velázquez

GUTIÉRREZ LLORET, S. (1996-b): "El aprovechamiento agrícola de las zonas húmedas: la introducción de arcaduz en el sureste de Al-Andalus (siglos VIII y IX)", Arqueología y Territorio Medieval, 3. Universidad de Jaén, pp. 7-19.

GUTIÉRREZ LLORET, S. (2013): "De Teodomiro a Tudmir. Los primeros tiempos desde la arqueología (S. VII-IX)" en Actas XXXIX Semana de Estudios Medievales, 2012. De Mahoma a Carlomagno, Estella, Navarra. P. 229-283

JIMÉNEZ CASTILLO, P. (2001): Murcia islámica. Una visión a través de la arqueología. Ayuntamiento de Murcia.

JIMÉNEZ CASTILLO, P., NAVARRO PALAZÓN, J. (2001): "Murcia Omeya" en El esplendor de los Omeyas cordobeses. La civilización musulmana de Europa occidental, p. 132-151. Exposición en Madinat al-Zahra, del 3 de mayo al 30 de septiembre de 2001.
JIMÉNEZ CASTILLO, P (2013): De la Antigüedad al Islam. Murcia. (Tésis Doctoral: http://digital.csic.es/handle/10261/95860).

KIRCHNER, H.; NAVARRO, C. (1993): "Objetivos, método y práctica de la arqueología hidráulica”. Arqueología y territorio Medieval, 1, (1994), pp. 159-182.

KIRCHNER, H. (2010): "Arqueologia hidràulica i tipologia d'espais irrigats andalusins." III Curs Internacional d'Arqueologia Medieval. La prospecció i el territori. LleidaAlgerri 13-14 de marzo de 2008, p. 129-146.

LÓPEZ MEDINA, M.J. (1996): "El agua en el sureste peninsular durante época romana. Su aprovechamiento para la agricultura", en Agricultura y regadio en al-Andalus. II Coloquio Historia y Medio Físico. Almería, pp. 13-16

LUCKHARD, F. (1914): Das privathaus im ptolemäischen und römischen Ägypten. Giessen.

MALPICA CUELLO, A. (1991): "El complejo hidráulico de los Albercones", Cuadernos de la Alhambra, 27, pp. 65-101.

MALPICA CUELLO, A. (Ed.). (1993): La cerámica altomedieval en el sur de al-Andalus. Primer Encuentro de Arqueología y Patrimonio, 1991 Salobreña (Granada).

MALPICA CUELLO, A. (1995): "El agua en al-Andalus. Un debate historiográfico y una propuesta de análisis", en $V$ Semana de Estudios Medievales (Nájera, 1 al 15 de agosto de 1994), p. 65-86.

MANCHA, R., (1836): Memoria sobre la población y riegos de la Huerta de Murcia, Imprenta de Mariano Bellido, Murcia.

MANZANO MARTÍNEZ, E. (1986): "El regadío en al-Andalus: problemas en torno a su estudio", España Medieval, 8, pp. 617-632.

MARTÍ, R. (1989): "Oriente y Occidente en las tradiciones hidráulicas medievales", El agua en zonas áridas: Arqueología e Historia: I Coloquio de Historia y Medio Físico. Instituto de Estudios Almerienses. Departamento de Historia, p. 421-440.

MOLINA LÓPEZ, E. (1972). "La Cora de Tudmīr según al Udri (s. XI). Aportaciones al estudio geográfico descriptivo del SE peninsular". C.H.I., n 3, Granada.

MONTANER SALAS, M.E. (1982). Norias, aceñas, artes y ceñiles en las vegas murcianas del Segura y Campo de Cartagena. Biblioteca Básica Murciana, 4. Ed. Regional de Murcia. Pg. 54.

MUÑOZ LÓPEZ, F., (1992): "Nuevos datos sobre urbanismo y alfarería medieval en Murcia", Verdolay, 4, pp. 175-184.

NAVARRO PALAZÓN, J. (1986): La cerámica islámica en Murcia. Volumen I: Catálogo. Murcia.

NAVARRO PALAZÓN, J. (1990): "Los materiales islámicos del alfar antiguo de San Nicolás de Murcia”, en Fours de Poitiers et "testares" médiévaux en Méditerranée occidentale. Publications de la Casa de Velázquez, Série Archéologie XIII, p. 29-43 
NAVARRO PALAZÓN, J., ROBLES FERNÁNDEZ, A. (1993): "El baño árabe de San Nicolás de Murcia" en Memorias de Arqueología, 4 (1990), p. 330-339

NAVARRO PALAZÓN, J., JIMÉNEZ CASTILLO, P. (1998): "Siyāsa: estudio arqueológico del despoblado andalusí (ss. XI-XIII)" en SALMERÓN, F., SALMERÓN, J. (Ed.), Materiales de Historia Local. Cieza. P. 99-113.

NAVARRO PALAZÓN, J., JIMÉNEZ CASTILLO, P. (2003): "La cerámica andalusí de Siyâsa. Estudio preliminar" en Cerâmica Medieval e Pós-Medieval, métodos e resultados para o seu estudo, Actas das 3a Jornadas Tondela (Portugal), 1997, p. 103-123

NAVARRO PALAZÓN, J., JIMÉNEZ CASTILLO, P. (2007): Siyāsa: estudio arqueológico del despoblado andalusí (sS. XI-XIII). El Legado Andalusí.

NAVARRO PALAZÓN, J., JIMÉNEZ CASTILLO, P. (2008) “El agua en la ciudad andalusí", en SOBRINO SIMAL, J., CERVERA POZO, L. (Ed.) $2^{\circ}$ Coloquio Internacional Irrigación, Energía y Abastecimiento de Agua: La Cultura del Agua en el Arco Mediterráneo. P. 147-254.

NAVARRO PALAZÓN, J., JIMÉNEZ CASTILLO, P. (2011): "Materiales y técnicas constructivas en la Murcia andalusí (siglos X-XIII), Arqueología de la Arquitectura, 8, C.S.I.C., p. 85-120.

OJEDA CALVO, R. (2006): "La Rota del Museo de Huelva: apuntes sobre el origen, adscripción, uso y funcionalidad de una rueda para evacuación de agua hallada en Minas de Riotinto." En La rueda elevadora de agua de las minas de Riotinto: memoria de intervención, PH Cuadernos, 18, Sevilla (Coord. Científicos Pedro E. Manzano Beltrán y Reyes Ojeda Calvo) p. 10-39

PASCUAL PACHECO, J., RIBERA, A., ROSELLÓ, M. (2003): "Cerámica de la ciudad de Valencia entre la época visigoda y omeya (siglos VI-X)" en CABALLERO, L., MATEOS, P., RETUERCE, M. (Ed.), Cerámicas tardorromanas y altomedievales en la Península Ibérica. Anejos de Archivo Español de Arqueología XXVIII. P. 67-118

PÉREZ VALERA, F. (e.p.): "Estudio geológico y sedimentológico de los materiales sedimentarios relacionados con el yacimiento arqueológico <<Senda de Granada $>$, Espinardo (Murcia)".

POCKLINTONG, R. (1985): "Acequias árabes y pre-árabes en Murcia y Lorca: Aportación toponímica a la historia del regadío", X Col.loqui General de la Societat d'Onomástica, Valencia. P. 462-473

POCKLINTONG, R. (1990): Estudios toponímicos en torno a los orígenes de Murcia. Biblioteca Murciana de Bolsillo, Academia Alfonso X el Sabio. Murcia.

POZO MARTíNEZ, I. (1989): "El despoblado islámico de Calasparra (Murcia). Memoria preliminar”, Miscelánea Medieval Murciana, vol. XV, p. 186-212.

POZO MARTÍNEZ, I. (1991). "Un baño privado islámico en la calle Polo de Medina (Murcia)”. Verdolay, n³, Murcia. Pp. 79-94).
POZO MARTÍNEZ, I (1999): "Arqueología y arquitectura islámicas en el Monasterio de Santa Clara la Real (Murcia)", Catálogo de la exposición: Paraísos Perdidos. Patios y Claustros. Murcia, pp. 53-104.

RAMÍREZ ÁGUILA, J.A., MARTíNEZ LÓPEZ, J.A. (1996): "Hidráulica urbana de una madina agrícola. Murcia, siglos XI-XIII", Agricultura y regadio en al-Andalus: II Coloquio de Historia y Medio Físico, Almería, pp.133-150

RETUERCE VELASCO, M. (1998): La cerámica andalusí de la Meseta, Madrid.

REKLAITYTE, I. (2006): "Acerca de las mudum andalusíes", SALDVIE, n 6, pp. 225-249

RIAD, R. (1964): "Tomb Paintings from the Necropolis of Alexandria", Archeology XVII.

ROBLES FERNÁNDEZ, A., NAVARRO SANTA-CRUZ, E., MARTÍNEZ ALCALDE, M. (1995):"Sistemas hidráulicos y transformaciones urbanas en el sector oriental de Mursiya. Informe preliminar de la intervención realizada en la Plaza de Las Balsas, no 15" Memorias de Arqueología, 10, pp. 534-551.

ROBLES FERNÁNDEZ, A. (2006): Ingenios hidráulicos en la Murcia árabe. Ayto. de Murcia.

RODZIEWICZ, M. (1984): Alexandrie III: Les habitations romaines tardives d'Alexandrie. Warsaw

ROSSELLÓ BORDOY, G., (1978): Ensayo de sistematización de la cerámica árabe en Mallorca. Palma de Mallorca.

ROSSELLÓ BORDOY, G. (1993): "Las cerámicas de primera época: algunas observaciones metodológicas" en MALPICA CUELLO, A. (Ed.) La cerámica Altomedieval en el sur de al-Andalus. Granada, p. 14-35.

ROSSELLÓ VERGER, V.M., CANO GARCÍA, G.M. (1974): "Un parcelario geométrico cuestionable: la Huerta y la ciudad de Murcia" Estudios sobre centuriaciones romanas en España.

SALVADOR VENTURA, F. (1989): "La agricultura de regadío durante la Antigüedad Tardía en el sur de la Península Ibérica", en El agua en zonas áridas: Arqueología e Historia: I Coloquio de Historia y Medio Físico, Almería, pp.407-418.

SCHIØLER, T. (1973): Roman and islamic wáter-lifting wheels. Lund.

SCHIØLER, T. (2012): Photo collection about water-lifting devides. Url: http://www.kattler.dk/schiolers/uk/index. html

TORRES FONTES, J.; CODOM II.

TORRES FONTES, J. (1975): El regadío murciano en la primera mitad del siglo XIV. Junta de Hacendados. Murcia.

TORRES FONTES, J. (1990): Repartimiento y Repoblación de Murcia en el siglo XIII. Murcia.

VALLEJO TRIANO, A., ESCUDERO ARANDA, J. (1999): "Aportaciones para una tipología de la cerámica común califal de Madinat al-Zahra”. Arqueología y Territorio Medieval, 6. Universidad de Jaén. 